\title{
LUT
}

University

\section{Ultra-desulfurization of sulfur recovery unit wastewater using thin film nanocomposite membrane}

\author{
Azizi Namaghi Hamed, Pourafshari Chenar Mahdi, Haghighi Asl Ali, Esmaeili \\ Mohammadamin, Pihlajamäki Arto, Kallioinen Mari, Mänttäri Mika
}

This is a Post-print version of a publication

published by Elsevier

in Separation and Purification Technology

DOI: $10.1016 / j . s e p p u r .2019 .03 .096$

Copyright of the original publication: ( 2019 Elsevier

Please cite the publication as follows:

Azizi N.H., Pourafshari C.M., Haghighi A.A., Esmaeili M., Pihlajamäki A., Kallioinen M., Mänttäri M. (2019). Ultra-desulfurization of sulfur recovery unit wastewater using thin film nanocomposite membrane. Separation and Purification Technology, vol. 221. pp. 211-225. DOI: 10.1016/j. seppur.2019.03.096

This is a parallel published version of an original publication. This version can differ from the original published article. 


\section{Ultra-desulfurization of sulfur recovery unit wastewater using thin film nanocomposite membrane}

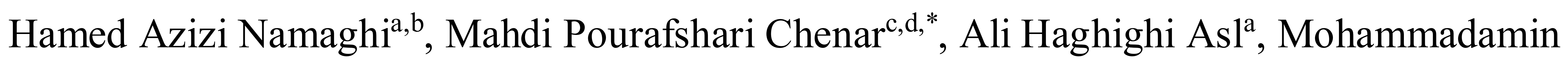
Esmaeili ${ }^{\mathrm{b}}$, Arto Pihlajamäki ${ }^{\mathrm{b}}$, Mari Kallioinen, ${ }^{\mathrm{e}, \mathrm{b}}$, Mika Mänttärib

${ }^{a}$ Faculty of Chemical, Petroleum and Gas Engineering, Semnan University, Semnan 3513119111, Iran

${ }^{b}$ LUT School of Engineering Science, Lappeenranta University of Technology, P.O. Box 20, 53850 Lappeenranta, Finland

${ }^{c}$ Chemical Engineering Department, Faculty of Engineering, Ferdowsi University of Mashhad, Mashhad 9177948944, Iran

${ }^{d}$ Research Center of Membrane Processes and Membrane, Faculty of Engineering, Ferdowsi University of Mashhad, Mashhad 9177948944, Iran

${ }^{e}$ LUT Re-Source Platform, Lappeenranta University of Technology, P.O. BOX 20, 53851 Lappeenranta, Finland

\section{Abstract}

Herein, to meet the requirement of the stringent sulfur emission and discharge rate standards based on World Health Organization (WHO) and Environmental Protection Agency (EPA), polyamide/titanium dioxide $\left(\mathrm{PA} / \mathrm{TiO}_{2}\right)$ thin fi $\mathrm{lm}$ nanocomposite $(\mathrm{TFN})$ membranes were synthesized to remove sulfur compound from sulfur recovery unit (SRU) wastewater. The experiments were designed to appraise the effects of three independent factors including $\mathrm{TiO}_{2}$ nanoparticle concentration, transmembrane pressure (TMP), and operating temperature on membrane performance. Surface physiochemical and morphological properties of the resultant membranes were characterized with analytical techniques. The membrane characterizations revealed that the nanocomposite selective layer was formed on the surface of the substrate and its morphology and surface charge were affected by $\mathrm{TiO}_{2}$ loading. The performance test showed that TFN membrane was highly effective in sulfur removal as the minimum and maximum rejections with this type of membrane in the design space were $92.56 \%$ and $99.94 \%$, respectively. In addition, the responses were predicted by the model equations designed via response surface methodology (RSM). Accordingly, the main effects and their interactions were statistically validated by the analysis of variance 
(ANOVA). In conclusion, the resulting TFN membranes demonstrated not only a very outstanding reduction in sulfur content (more than 97\% below the aforementioned global surveillance standards' level), but also overcame the trade-o ff effect between permeability and selectivity of the reference TFC membranes.

Keywords: Ultra-desulfurization; Sulfur recovery unit; Thin film nanocomposite membrane; Titanium dioxide; Antifouling characteristic; Analysis of variance.

\section{Introduction}

Sulfur is one of the most perilous pollutants in air and water that may be present in different environmental compartments in the form of various chemical compounds, such as carbon disulfide $\left(\mathrm{CS}_{2}\right)$, carbonyl sulfide (COS), dimethyl sulfide (DMS), hydrogen sulfide $\left(\mathrm{H}_{2} \mathrm{~S}\right)$, mercaptans $(\mathrm{RSH})$, sulfides $\left(\mathrm{S}^{2-}\right)$, sulfates $\left(\mathrm{SO}_{4}^{2-}\right)$, thiophenes $\left(\mathrm{C}_{4} \mathrm{H}_{4} \mathrm{~S}\right)$, and thiosulfates $\left(\mathrm{S}_{2} \mathrm{O}_{3}^{2-}\right)$ [1]. The main sources of sulfur compounds production are oil and gas refineries, petrochemical industries, power plants, coal mines, factories, acid rains, volcanoes, and also transportation systems which are somehow related to fossil fuels. Other industries that have to manage the creation and treatment of sulfur are water treatment, landfill gas processing, manure handling, and pulp and paper. Sulfur compounds are often toxic, smelly and irritating. Thus, their inhalation and contact with eyes and skin must be avoided. In wastewater treatment, sulfur compounds tend to be relatively low concentration, yet high enough to cause issues with safety, corrosion of equipment, and odor complaints. From environmental point of view, sulfur which is not only detrimental for plants and aquatic life, but also damages water resources through the diffusion into the groundwater aquifers [2]. Due to increasing environmental concerns, stringent limits on sulfur levels in aqueous media are being executed world over to achieve target of sulfur below $250 \mathrm{mg} / \mathrm{L}$. Consequently, the necessity of developing an effective wastewater desulfurization process is highly demanded. 
Several treatment techniques have been developed to reduce the concentration of sulfur toxicants from aqueous media. These techniques generally include biological treatment [3-5], root zone process by plant shoots [6], reducing sulfur compound to sulfide as an electron carrier [7], oxidation treatment [8-10], chemical treatment methods such as using 1-butyl-3-methylimidazolium chloride and organic solvent [11, 12], adsorption [13], and also reaction with supercritical alcohols [14]. Moreover, Mochizuki et al. [15] used metal-loaded carbons to remove organic sulfur from coal extract. They found that all organic sulfur in the coal extract could be successfully removed using the nickel-loaded carbon at $350{ }^{\circ} \mathrm{C}$ and holding time of $8 \mathrm{~h}$. In another research, Jin et al. [16] used trichloroacetic acid (TCA) as a catalyst combined with ultrasonic waves for the desulfurization of coal tar pitch (CTP) by oxidation with hydrogen peroxide and they reported the influence of catalysts and reaction conditions on desulfurization of CTP. Furthermore, sulfur removal from six original, three hydrochloric acid treated and three demineralized lignite samples by pyrolysis process at seven different temperatures between 350 and $950{ }^{\circ} \mathrm{C}$ for $7 \mathrm{~min}$ under evolved gas atmosphere was investigated by Uzun et al. [17]. They clearly expressed that high pyrolysis temperatures favour total sulfur removal for all lignites, reaching $30-54 \%$ around 850 to $950{ }^{\circ} \mathrm{C}$. The maximum total sulfur removal from acid treated lignites was observed as $77 \%$.

Although extensive research has been carried out on desulfurization, all the previously mentioned methods suffer from some serious limitations, such as secondary pollution of deposition, inconvenient operation and high cost and energy consumption. In order to defeat such problems, pressure driven membrane separation processes are offered in water and wastewater treatment systems. Hereon, Yin et al. [18] applied integrated membrane process for desulfurization of wastewater generated in the coking industry. They observed that the proposed process is technically feasible and economically efficient for wastewater desulfurization. Therefore, membrane technology has generated renewed interest in the two last decades in many emerging applications due to its flexibility, low cost, easy operation, low space requirements, easy to scale up, energy efficient, clean and environmental friendliness [19]. However, the major intrinsic drawbacks in the extensive use of membranes during 
operation are concentration polarization and fouling phenomena, which result in flux decline, feed TMP increase, product quality decrease, and ultimately shortened productive membrane life [20]. One approach for defeating such kind of problems and improving the performance of membrane is the application of nanotechnology enhanced membrane materials.

Thin film composite (TFC) are semipermeable membranes which are prepared mainly to be used in desalination, water purification, and wastewater treatment applications. As nanotechnology is developing, the applicability of TFC membranes has been extended. Accordingly, scientists have taken the advantage of nanotechnology in preparation of TFN membranes by incorporating the nanomaterials as filler into thin film layer of composite membranes to minimize their fundamental limitations in water and wastewater treatment $[21,22]$. It is now well established from a variety of studies that the performance of TFC membranes is enhanced by embedding inorganic nanoparticles (NPs), such as silica dioxide $\left(\mathrm{SiO}_{2}\right)$ NPs $[23,24]$ into the PA layer. Many researchers have also modified the composite membranes by incorporating $\mathrm{TiO}_{2} \mathrm{NPs}$ or its modified forms into the top thin selective layer [25-29] or its substrate [30].

Moreover, comprehensive studies on the application of some other inorganic nanomaterials including zeolites, graphene, and carbon nanotube (CNT) in TFC membrane preparation have been conducted by Rodriguez-Calvo et al. [31] and Daer et al. [32]. In a follow-up study, Namvar-Mahboub et al. [22] utilized amino-functionalized UZM-5 nanoparticles in fabrication of zeolite-based TFN membrane for organic solvent nanofiltration (OSN) process. Their results demonstrated that the existence of UZM-5 in the PA selective layer improved both oil rejection and permeate flux under optimal concentration $(0.02 \% \mathrm{w} / \mathrm{v}$ of UZM-5). In the same vein, Jadav et al. [33] stated that a certain amount of silica loading into the PA layer can substantially improve the thermal stability and TFC membrane performance.

In our previous study [34], the impact of different critical parameters in the preparation of TFC membrane including casting thickness, polymer concentration, m-phenylenediamine soaking time, 
curing time, curing temperature, and interfacial polymerization (IP) time have been identified and optimized using fractional factorial design (FFD) and response surface methodology (RSM). In addition, different design of experiment approaches to predict and optimize various parameters which affect the performance of TFC membranes have been studied [35-38].

Among various metal oxide nanoparticles, titanium dioxide has been drawn the scientists' attention due to its outstanding chemical stability, antibacterial property, availability, hydrophilicity, and photocatalytic effect. Besides, $\mathrm{TiO}_{2}$ nanoparticles are useful in handling the fouling problem of membrane processes as it can effectively degrade foulants, particularly under the UV irradiation [39]. Taken together, it is expected that the performance of TFC membranes, permeate flux and separation efficiency, can be improved by surface modification incorporated with nanoparticles.

To the best of the authors' knowledge, sulfur treating evaluation by TFN membranes has not been investigated in existing literature up to now. Therefore, high effort was put into preparation and characterization of pristine and modified TFC membranes and also testing their performance in desulfurization of sour wastewater obtaining from sulfur recovery unit. The fouling resistance of the TFN membrane was also evaluated by flux decline analysis method. The as-prepared TFN membranes were also characterized by attenuated total reflection Fourier transform infrared (ATRFTIR) spectroscopy, scanning electron microscopy (SEM), contact angle and surface charge measurements. Furthermore, the main and interaction effects of three significant factors, namely concentration of $\mathrm{TiO}_{2}$ nanoparticle, TMP, and operating temperature were experimentally investigated on the performance of the as-prepared TFN membranes. For this purpose, a three-factor, three-level RSM predictive model was statistically developed based on central composite facecentered (CCF) analysis.

This study aims to contribute to this growing area of research by providing new and valuable scientific information regarding the use of nanofiltration (NF) in order to evaluate it as a potential technique for the separation of sulfur compounds from industrial wastewaters. 


\section{Materials and methods}

\subsection{Chemicals}

The non-woven polyester (PET) fabric was obtained from an old reverse osmosis (RO) spiral wound modules. Polysulfone (PSf) and N-methyl-2-pyrrolidone (NMP) were provided by BASF and Merck, respectively. The main functional monomers including 1,3,5-benzenetricarbonyl trichloride (TMC, purity 98\%) and 1,3-phenylenediamine (MPD, purity 99\%) were supplied by Aldrich. $\mathrm{TiO}_{2}$ nanoparticles with mean particle size of $25 \mathrm{~nm}$ were supplied by Degussa. Deionized (DI) water and n-hexane were obtained from a 5-stage water purification system (Aqua spring) and Merck, respectively. Sodium hypochlorite solution (6-14\% active chlorine) was purchased from Merck and was used to remove the PA layer in order determine the real content of embedded $\mathrm{TiO}_{2} \mathrm{NPs}$ within the PA structure. All chemicals were used without further purification. The wastewater samples in the present work were provided by Shahid Hasheminejad gas refinery Co. which treats one of the sourest natural gas in the Middle East. It should be noted that, Middle East has the world's most sour gas reserves.

\subsection{Preparation of TFN membrane}

The PSf substrate was fabricated via non-solvent induced phase separation (NIPS) method. The PSf solution was prepared in NMP at desired concentration (16 $\mathrm{wt} \%)$. The well mixed, bubble free solution was cast with predetermined thickness $(200 \mu \mathrm{m})$ by adjustable casting bar (Neurtek2281205) onto the PET nonwoven fabric. The membrane was immediately immersed into the precipitation bath containing DI water at room temperature. Various loadings of $\mathrm{TiO}_{2}$ nanoparticles $(0.02,0.04$ and 0.1 $\mathrm{wt} \%$ ) were added and dispersed homogeneously in the $0.1 \mathrm{wt} \% \mathrm{TMC}$ in $\mathrm{n}$-hexane solution by stirring and sonication for $30 \mathrm{~min}$ at $25^{\circ} \mathrm{C}$. With respect to the $\mathrm{TiO}_{2}$ loading, the resultant $\mathrm{TFN}$ membranes were denoted TFC or TFN0.00 (without TiO 2 ), TFN0.02, TFN0.04 and TFN0.1. 
Afterwards, the PSf support membrane was immersed in an aqueous solution of $2 \% \mathrm{w} / \mathrm{v}$ MPD for 1 min. The saturated membrane was pulled up slowly and its surface was firmly pressed with a soft rubber roller to eliminate remaining droplet and excess solution. The saturated composite membrane was subsequently exposed to the organic phase of TMC (formerly prepared) for $30 \mathrm{~s}$ to react with the residual MPD to form the PA layer. Restricting the MPD $(2 \% \mathrm{w} / \mathrm{v})$ and TMC $(0.1 \% \mathrm{w} / \mathrm{v})$ concentrations was required to produce a PA TFN membrane with a good combination of permeate flux and solute rejection [40]. Finally, the membrane was cured and dried in an air-circulation oven during specific period of time $(5 \mathrm{~min})$ and temperature $\left(60^{\circ} \mathrm{C}\right)$.

Low dosages of $\mathrm{TiO}_{2}$ NPs (0.02 and $0.04 \mathrm{wt} \%$ of TMC solution) were applied in preparation of TFN membranes as the PA layer thickness is around $200 \mathrm{~nm}$ and it is usually advisable to select low loading of nanoparticles in order to incorporate into the PA layer for TFN membrane preparation. At high loading, the partial aggregation of nanoparticles can take place due to hydrogen bonding, and thus their role in the separation process can be disrupted due to the formation of non-selective voids. In other words, there is no continuous dense PA structure on the surface of the substrate membrane to separate solute compounds from wastewater [22, 26, 39]. This point of view is also supported by Lai et al. (2016) who introduced titanate nanotubes as a nanofiller $(0.05$ or $0.10 \mathrm{w} / \mathrm{v} \%)$ in the selective layer of TFN. Their results demonstrate that at an optimum nanofiller loading $(0.05 \mathrm{w} / \mathrm{v} \%)$, membrane with higher pure water flux, $\mathrm{Na}_{2} \mathrm{SO}_{4}$ rejection, and antifouling characteristics can be achieved [28].

\subsection{Membrane characterization}

ATR-FTIR (spectrometer Perkin Elmer Frontier system with universal ATR module, Diamond crystal, USA) spectra were collected over a wavenumber range of $4000-400 \mathrm{~cm}^{-1}$ with spectral resolution of $4 \mathrm{~cm}^{-1}$ and 4 scans with a data interval of $1 \mathrm{~cm}^{-1}$ for each spectrum. At least three different locations were randomly selected and the average of those has been considered for each sample. Baseline correction was performed to obtain good results. It is essential to note that the membrane samples were completely air dried in desiccator before IR analysis. 
The surface morphology of ridge and valley or nodular structure of PA-TFC membranes were investigated using SEM (Hitachi SU 3500, Japan). The acceleration voltage was set to $15 \mathrm{kV}$. Since polymers are generally insulators, membrane samples have to be sputtered under vacuum with a thin layer of gold in Au sputtering system (Edwards, scancoat six) for producing electrical conductivity, elimination surface charging, and also minimization sample damage caused by the electron beam.

Furthermore, the elemental composition of membrane surfaces was measured using Energy Dispersive X-ray (EDX) Spectroscopy and has been used in order to evaluate the degree of crosslinking of PA layer.

Quantitative and qualitative surface roughness of the TFC and TFN membranes was measured using AFM (Easyscan2 Flex AFM, Switzerland) with tapping mode in air and has been used in order to evaluate the membrane surface roughness.

Surface hydrophilicity of PSf and PA layers was evaluated by measuring the average equilibrium sessile drop contact angles of DI water via KSV instrument CAM 101. In this method, the membrane samples were air-dried overnight at room temperature in a desiccator. Afterwards, they were completely attached on a clean glass plate (using double-sided bonding tape) and at least 5 various droplets of DI water were produced on different volume (below $5 \mu \mathrm{L}$ ). The images were taken at room temperature using an imaging source model DMK 21F04. Images were analyzed based on statistic measurement and Young/Laplace fitting methods.

The membrane surface charge is one of the most relevant influencing factors in aqueous filtration processes and is related to the zeta potential. The zeta potential of membranes was measured by an electro-kinetic analyzer (SurPASS, Anton Paar, Austria) with an adjustable gap cell and using $1 \mathrm{mM}$ $\mathrm{KCl}$ as background electrolyte solution. The membrane pieces were stored in DI water in a fridge (about $5{ }^{\circ} \mathrm{C}$ ) prior to use. The solution $\mathrm{pH}$ was first shifted to about 8 by dilute $\mathrm{KOH}$ solution and then automatically titrated from 8 to 3 using $0.05 \mathrm{M} \mathrm{HCl}$ solution during the analysis. Finally, the 
zeta potential was calculated from streaming current measurement according to the classic Helmholtz-Smoluchowski equation [41].

$\zeta=\frac{d l}{d p} \times \frac{\eta}{\varepsilon \times \varepsilon_{0}} \times \frac{L}{A}$

where $\mathrm{d} l / \mathrm{dp}$ is the slope of streaming current versus pressure, $\eta$ is the liquid viscosity (viscosity of pure water at room temperature about $20^{\circ} \mathrm{C}$ ), $\varepsilon_{0}$ is the vacuum permittivity, and $\varepsilon$ is the dielectric constant of electrolyte (water at the same temperature), $\mathrm{L}$ is the length of streaming channel, $\mathrm{A}$ is the cross section of streaming channel.

The inductively coupled plasma optical emission spectrometry (ICP-OES) (Model 76004555, Spectro Arcos System) was used in order to evaluate the real content of the titanium (Ti) element in the TMC solution and PA layer of nanocomposite membranes. For this purpose, three strips of a specific size ( $5 \mathrm{~cm}$ in diameter) of each TFN membranes (TFN0.02 and TFN0.04) were exposed with $0.1 \mathrm{~L}$ sodium hypochlorite $(\mathrm{NaOCl})$ aqueous solution and shook well for $300,000 \mathrm{ppm} . \mathrm{h}$ at $30^{\circ} \mathrm{C}$.

\subsection{Experimental design and procedure}

All NF experiments were carried out by stainless steel cross-flow filtration system with a feed volume of $1000 \mathrm{~mL}$. The effective filtration area of the membrane was $8.04 \mathrm{~cm}^{2}$. The operating temperature was controlled by using coiling system containing cooling water and an electrical coil. Details of this setup were described previously [34]. In this regard, the membranes were pressurized for $1 \mathrm{~h}$ with DI water before each test. Then, the performance of each clean synthesized membranes was investigated through measuring both stable permeate flux (SPF) and sulfur rejection efficiency (SRE). The permeate samples were collected continuously and gravimetrically to evaluate the performance of membranes after $2 \mathrm{~h}$ from the beginning of the experiment. The permeate flux, $\mathrm{J}_{\mathrm{p}}\left(\mathrm{L} \cdot \mathrm{m}^{-2} \cdot \mathrm{h}^{-1}(\mathrm{LMH})\right)$, was calculated using the following equation:

$J_{p}=\frac{1}{A} \frac{d V}{d t}$ 
where $V(\mathrm{~L})$ is the volume of permeate; $A\left(\mathrm{~m}^{2}\right)$ is the membrane effective area in the membrane module; and $t(\mathrm{~h})$ is the sampling time.

The antifouling characteristics of the membranes were evaluated by calculation of flux recovery ratio (FRR), reversible fouling ratio $\left(\mathrm{R}_{\mathrm{r}}\right)$, irreversible fouling ratio $\left(\mathrm{R}_{\mathrm{ir}}\right)$ and total fouling ratio $\left(\mathrm{R}_{\mathrm{t}}\right)$ based on the following equations $[42,43]$ :

$$
\begin{aligned}
& \operatorname{FRR}(\%)=\left(\frac{J_{w 2}}{J_{w 1}}\right) \times 100 \\
& R_{r}=\left(\frac{J_{w 2}-J_{p}}{J_{w 1}}\right) \times 100 \\
& R_{i r}=\left(\frac{J_{w 1}-J_{w 2}}{J_{w 1}}\right) \times 100 \\
& R_{t}=R_{r}+R_{i r}=\left(1-\frac{J_{p}}{J_{w 1}}\right) \times 100
\end{aligned}
$$

where $\mathrm{J}_{\mathrm{w} 1}(\mathrm{LMH})$ is the initial pure water flux (PWF) of the new membranes, $\mathrm{J}_{\mathrm{w} 2}(\mathrm{LMH})$ is the PWF of the fouled membranes after renewal of the membrane surface by washing with DI water. In the analysis of membrane fouling, PWF of the cleaned membranes were initially tested for $1 \mathrm{~h}\left(\mathrm{~J}_{\mathrm{w} 1}\right)$. The feed tank was subsequently refilled with sour wastewater. The permeate flux, $J_{p}$, was measured after $2 \mathrm{~h}$. After filtration of wastewater, the membranes were washed with distilled water for $10 \mathrm{~min}$, then the PWF of the fouled membrane was measured for $1 \mathrm{~h}$. It should be noted that all the fluxes were recorded when the variations of the flux decreased and approached steady state.

The concentration of sulfur in feed and permeate was analyzed by atomic absorption spectrometry (DR-5000 UV-visible, HACH Co., USA). In this procedure, all of the sulfur compounds in the wastewater are converted to sulfate ions, and afterwards $\mathrm{BaCl}_{2}$ is used during the analysis of sulfate. $\mathrm{BaCl}_{2}$ converts sulfate present in the solution to barium sulfate and the solution becomes turbid. 
Turbidity measurement gives the concentration of sulfate turns into barium sulfate. By this method, the concentration of sulfates in wastewater was in the range of 1500-2000 mg/L. Feed samples were stored in the fridge at temperature around $4{ }^{\circ} \mathrm{C}$ before experiments in order to minimize the possible degradation and deformation of sulfur compounds. Finally, SRE (\%) was determined using the following equation to evaluate the filtration efficiency:

$\%$ SRE $=\left(1-\frac{\left[S O_{4}^{2-}\right]_{p}}{\left[S O_{4}^{2-}\right]_{f}}\right) \times 100$

where $\left[\mathrm{SO}_{4}^{2-}\right]_{p}(\mathrm{mg} / \mathrm{L})$ and $\left[\mathrm{SO}_{4}^{2-}\right]_{f}(\mathrm{mg} / \mathrm{L})$ are the concentration of sulfate in permeate and feed, respectively.

One of the most significant objective of design of experiment (DOE) is to collect the maximum amount of dependent information with a minimum expenditure of time and resources. A central composite design (CCD) is the most commonly used response surface methodology for this purpose. CCD is a factorial or fractional factorial design with center points, augmented with a group of axial (star) points that let us estimate the curvature. CCD with different properties can be developed by taking different $\alpha$ values. CCF is a type of CCD with $\alpha= \pm 1$, in which a quadratic model is composed of the full $2^{3}$ factors with its 8 cubic points, augmented with six star points and three replications of the center points. The star points are placed on the face centers of the cube; therefore, each factor has only three levels instead of five in CCD. Augmenting an existing factorial or resolution V (five) design with appropriate axial points can also produce this design [44]. The CCF design for the three independent factors is schematized in Fig. 1. 


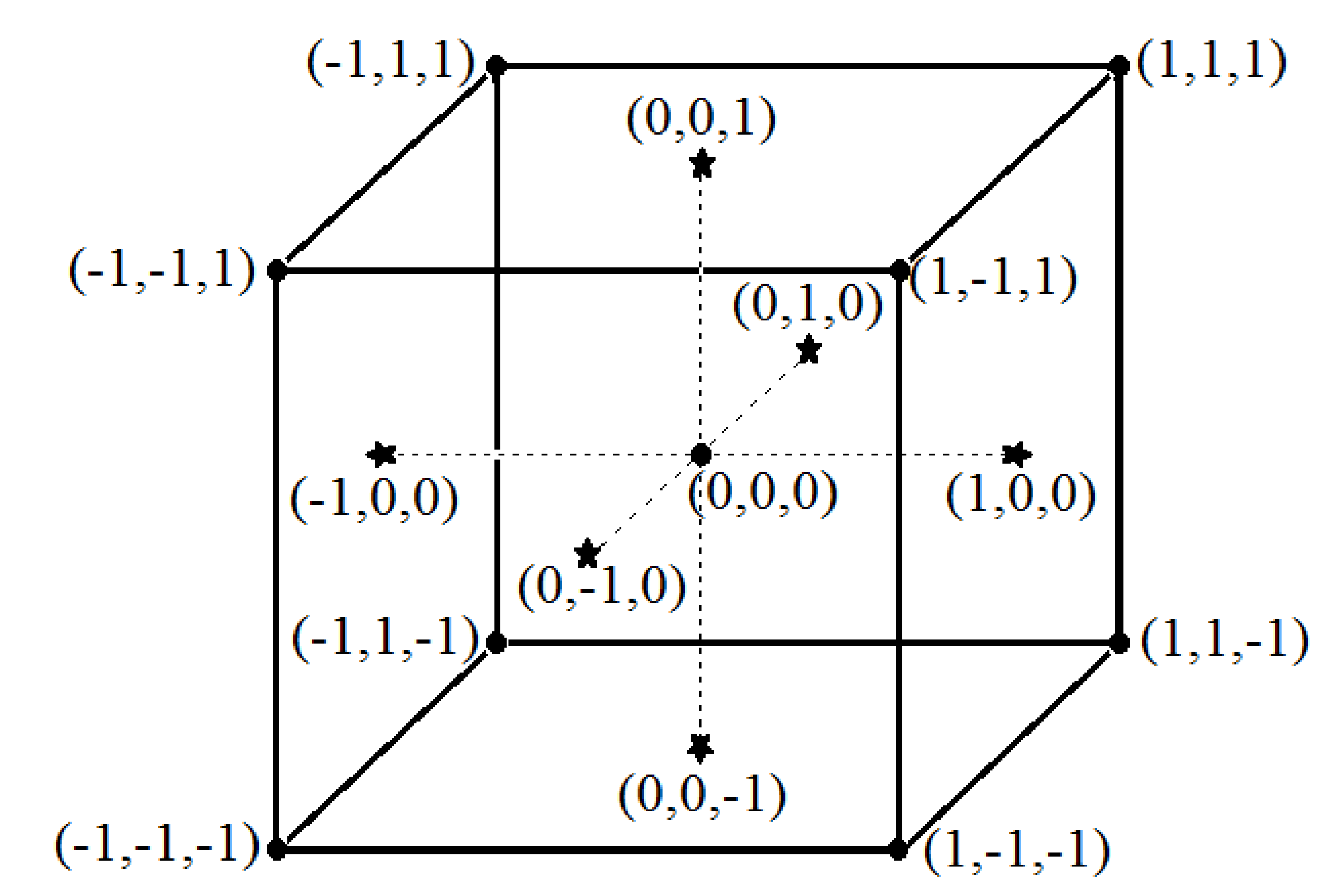

Fig. 1. Schematic of CCF design for the three factors.

Because there are only three levels, the quadratic model as follow is appropriate.

$y=\beta_{0}+\sum_{i=1}^{k} \beta_{i} x_{i}+\sum_{i<j} \beta_{i j} x_{i} x_{j}+\sum_{i=1}^{k} \beta_{i i} x_{i}^{2}$

where $y$ represents the predicted responses, $x_{i}$ and $x_{j}$ are the coded values of independent variables, $\beta_{0}$ is the regression term at the center point (intercept), $\beta_{i}$ is the linear main effect coefficients, $\beta_{i i}$ is the quadratic coefficients, and $\beta_{i j}$ is the two-factor interactions (2FIs) coefficients. This second-order polynomial equation was used to find the mathematical relationship between the dependent variables (SPF and SRE) and the set of independent variables (concentration of $\mathrm{TiO}_{2}$ nanoparticles, $\mathrm{TMP}$, and operating temperature). Also, the relation between dimensionless coded values of independent variables $\left(x_{i}\right)$ and actual values of them $\left(X_{i}\right)$ are defined as:

$x_{i}=\frac{X_{i}-\left(X_{i, \text { high }}+X_{i, \text { low }}\right) / 2}{\left(X_{i, \text { high }}-X_{i, \text { low }}\right) / 2}$

where $X_{i, \text { high }}$ and $X_{i, \text { low }}$ are the real values of the independent variable at high and low levels, respectively.

Briefly, the variable factors in this study with the coded and actual values at the levels set in the design are presented in Table 1. Each factor at two levels (high and low), and the center points, which are the midpoint between the high and low levels are repeated thrice. The model analysis was employed with the aid of Design Expert version 8.0.7.1 statistical software. 
Table 1. Actual design variables with real and coded values for the CCF.

\begin{tabular}{lccccc}
\hline & & & \multicolumn{3}{c}{ Real values of coded levels } \\
\cline { 4 - 6 } Factor & Symbol & Unit & $\begin{array}{c}-1 \\
\text { Low }\end{array}$ & $\begin{array}{c}\text { Center point } \\
\text { High }\end{array}$ \\
\hline$\left[\mathrm{TiO}_{2}\right]$ & $\mathrm{A}$ & $\mathrm{wt}^{\circ} \%$ & 0 & 0.02 & 0.04 \\
$\mathrm{TMP}$ & $\mathrm{B}$ & $\mathrm{bar}$ & 5 & 6 & 7 \\
Temperature & $\mathrm{C}$ & ${ }^{\circ} \mathrm{C}$ & 22 & 26 & 30 \\
\hline
\end{tabular}

The amount of $\mathrm{TiO}_{2}$ NPs as an essential variable was chosen in preparation of TFN membrane for wastewater treatment as it was hypothesized that it can have several useful effects on the performance of the membranes, e.g. improves the performance and overcome the trade-off effect between permeability and selectivity of the own TFC membranes due to its antifouling characteristic and hydrophilic nature.

Pressure has a direct relationship with power consumption in a way that by increasing the pressure, the power consumption will arise. The requirement of high pressure to the system usually leads to high operational cost, which limits the application of fabricated membranes. As a matter of fact, development of a novel and efficient TFN membranes with low operating pressure for different applications (water desalination and wastewater treatment) is still of high importance.

Ultimately, operating temperature was selected as it is an important factor in membrane processes which is related to solute solubility [45], mass transfer [46], concentration polarization [47], membrane fouling $[48,49]$ and membrane performance.

The corresponding CCF, consisting of 17 experiments, is shown in Table 2. Although with such cubical design, one or two center runs are sufficient to produce a reasonable stability of prediction variance, three replicates running at the design center were performed along the CCF in this study to check adequacy of curvature, analysis of repeatability, and provide an independent estimate of experimental error $[50,51]$. 
Table 2. Design layout and experimental points of the CCF.

\begin{tabular}{ccccc}
\hline $\begin{array}{c}\text { Experimental } \\
\text { ID }\end{array}$ & Run & \multicolumn{3}{c}{ Real input variable } \\
\cline { 3 - 5 } & & $\mathrm{A}$ & $\mathrm{B}$ & $\mathrm{C}$ \\
\hline 1 & 13 & 0.00 & 5 & 22 \\
2 & 6 & 0.04 & 5 & 22 \\
3 & 2 & 0.00 & 7 & 22 \\
4 & 14 & 0.04 & 7 & 22 \\
5 & 4 & 0.00 & 5 & 30 \\
6 & 7 & 0.04 & 5 & 30 \\
7 & 16 & 0.00 & 7 & 30 \\
8 & 3 & 0.04 & 7 & 30 \\
\hline 9 & 10 & 0.00 & 6 & 26 \\
10 & 12 & 0.04 & 6 & 26 \\
11 & 1 & 0.02 & 5 & 26 \\
12 & 5 & 0.02 & 7 & 26 \\
13 & 8 & 0.02 & 6 & 22 \\
14 & 11 & 0.02 & 6 & 30 \\
\hline 15 & 15 & 0.02 & 6 & 26 \\
16 & 17 & 0.02 & 6 & 26 \\
17 & 9 & 0.02 & 6 & 26 \\
\hline
\end{tabular}

\section{Results and discussion}

\subsection{FTIR analysis}

The representative functional groups in $\mathrm{PA}$ (with and without $\mathrm{TiO}_{2}$ nanoparticle) and $\mathrm{PSf}$ layers with magnification are shown in Fig. 2. Usually the penetration depth of IR radiation is greater than 300 $\mathrm{nm}$, at wavenumbers lower than $2000 \mathrm{~cm}^{-1}$. Nevertheless, the FTIR spectra reveals that the specific functional groups of PA can be detected over all TFC and TFN membranes which confirms the formation of a PA selective layer at the surface of the PSf substrate. Also, the chemical information of PA and PSf layers can be simultaneously obtained from as-prepared membranes as a result of the IR beam absorption. In this region, the IR spectrum of TFC membrane demonstrates two characteristic peaks at $1660 \mathrm{~cm}^{-1}$ and $1541 \mathrm{~cm}^{-1}$ which are mainly respected to primary amide band $(\mathrm{C}=\mathrm{O}$ stretching vibration of amide, $\mathrm{C}-\mathrm{N}$ stretching and $\mathrm{C}-\mathrm{C}-\mathrm{N}$ deformation vibration in a secondary amide group) and secondary amide band (in-plane $\mathrm{N}-\mathrm{H}$ bending motion and $\mathrm{C}-\mathrm{N}$ stretching vibrations of -CO-NH group), respectively. Other peaks are also observed at $1605 \mathrm{~cm}^{-1}, 1451 \mathrm{~cm}^{-1}$, and between 900 and $1200 \mathrm{~cm}^{-1}$ which are assigned to PA aromatic ring $(\mathrm{C}=\mathrm{C}$ ring stretching 
vibration and $\mathrm{N}-\mathrm{H}$ stretching of amide), carboxylic group $(\mathrm{C}=\mathrm{O}$ stretching and $\mathrm{O}-\mathrm{H}$ bending of carboxylic acid), and skeletal aliphatic $\mathrm{C}-\mathrm{C}$ /aromatic hydrogen bending and aliphatic $\mathrm{C}-\mathrm{H}$ rocking of PA, respectively [33, 52-56]. In addition, the peaks at 3333, 3214 and $1387 \mathrm{~cm}^{-1}$ are attributed to the carboxylic acid $(\mathrm{COOH})$, stretching $\mathrm{N}-\mathrm{H}$ amide and the mixture of $\mathrm{C}-\mathrm{N}$ stretching and in-plane $\mathrm{N}-\mathrm{H}$ deformation tertiary amide. It should be noted that the presence of carboxylic acid functional group resulting from the hydrolysis of third chloride to carboxylic acid, improving the hydrophilicity as well as water permeability of the membrane. In the case of PSf substrate, the main characteristic peaks were detected at $\sim 1585,1503$ and $1488 \mathrm{~cm}^{-1}$ which are attributed to aromatic in-plane ring bend stretching vibration $\left(\mathrm{CH}_{3}-\mathrm{C}-\mathrm{CH}_{3}\right.$ stretching), the peak at $1410 \mathrm{~cm}^{-1}$ is due to $\mathrm{C}=\mathrm{C}$ aromatic ring stretching, two weak peaks at 1387 and $1364 \mathrm{~cm}^{-1}$ which are solely presented in the spectrum of PSf associated with $\mathrm{C}-\mathrm{H}$ symmetric deformation vibration of $\mathrm{C}\left(\mathrm{CH}_{3}\right)_{2}$, the peaks at 1324 and $1295 \mathrm{~cm}^{-1}$ are assignable to the asymmetric $\mathrm{O}=\mathrm{S}=\mathrm{O}$ stretching vibration, the prominent peak at $1242 \mathrm{~cm}^{-1}$ is corresponded to asymmetric $\mathrm{C}-\mathrm{O}-\mathrm{C}$ stretching (vibration of aryl-O-aryl group), the peaks at 1169 and $1151 \mathrm{~cm}^{-1}$ are assigned to symmetric $\mathrm{O}=\mathrm{S}=\mathrm{O}$ stretching vibration, and finally the peak at $833 \mathrm{~cm}^{-}$ ${ }^{1}$ is related to hydrogen deformation of para-substituted phenyl groups in-phase out-of-plane. Also, peaks between $\sim 2900$ and $\sim 3100 \mathrm{~cm}^{-1}$ related to aromatic and aliphatic $\mathrm{C}-\mathrm{H}$ stretching vibrations [52, 57-60]. Moreover, all peaks of PSf substrate (with less intensity as a consequence of PA layer) are also visible in the IR spectra over a wavenumber range of $1800-800 \mathrm{~cm}^{-1}$.

In the presence of $\mathrm{TiO}_{2}$ nanoparticles, two types of interaction can be occurred between $\mathrm{PA}$ and $\mathrm{TiO}_{2}$ : (i) coordination interaction between carboxylic group of TMC monomer and the titanium atom and (ii) hydrogen bonding between surface hydroxyl group of $\mathrm{TiO}_{2}$ and carbonyl group. A schematic of probable interaction between $\mathrm{TiO}_{2}$ nanoparticles and PA matrix is shown in Fig. 3. Regarding these two interactions, peaks of TFN membranes have shifted slightly when compared to corresponding TFC membrane peaks. Furthermore, there are obvious reduction and promotion in intensity of PA and PSf characteristic bands, respectively. These relationships may partly be explained by less PA formation stemming from the presence of un-soluble solid $\mathrm{TiO}_{2}$ nanoparticles in $\mathrm{TMC}$ solution and 
complexation of $\mathrm{TiO}_{2}$ nanoparticles/PA matrix [22]. By way of illustration, analysis of the area of $\mathrm{OH}$ stretching exhibits $\mathrm{COOH}$ in TFC membrane $\left(3333 \mathrm{~cm}^{-1}\right)$ slightly shifted towards hydroxyl group $\left(3365 \mathrm{~cm}^{-1}\right)$ in TFN membranes. Also, the intensity of this peak decreased for TFN membranes. A possible explanation for this can be attributed to the high affinity of $\mathrm{TiO}_{2}$ nanoparticles to entrapped water molecules on the surface of TFN membranes [61]. Reduction of carboxylic acid concentration in PA layer by a bidentate coordination of carboxylate to $\mathrm{Ti}^{4+}$ is another possible explanation.

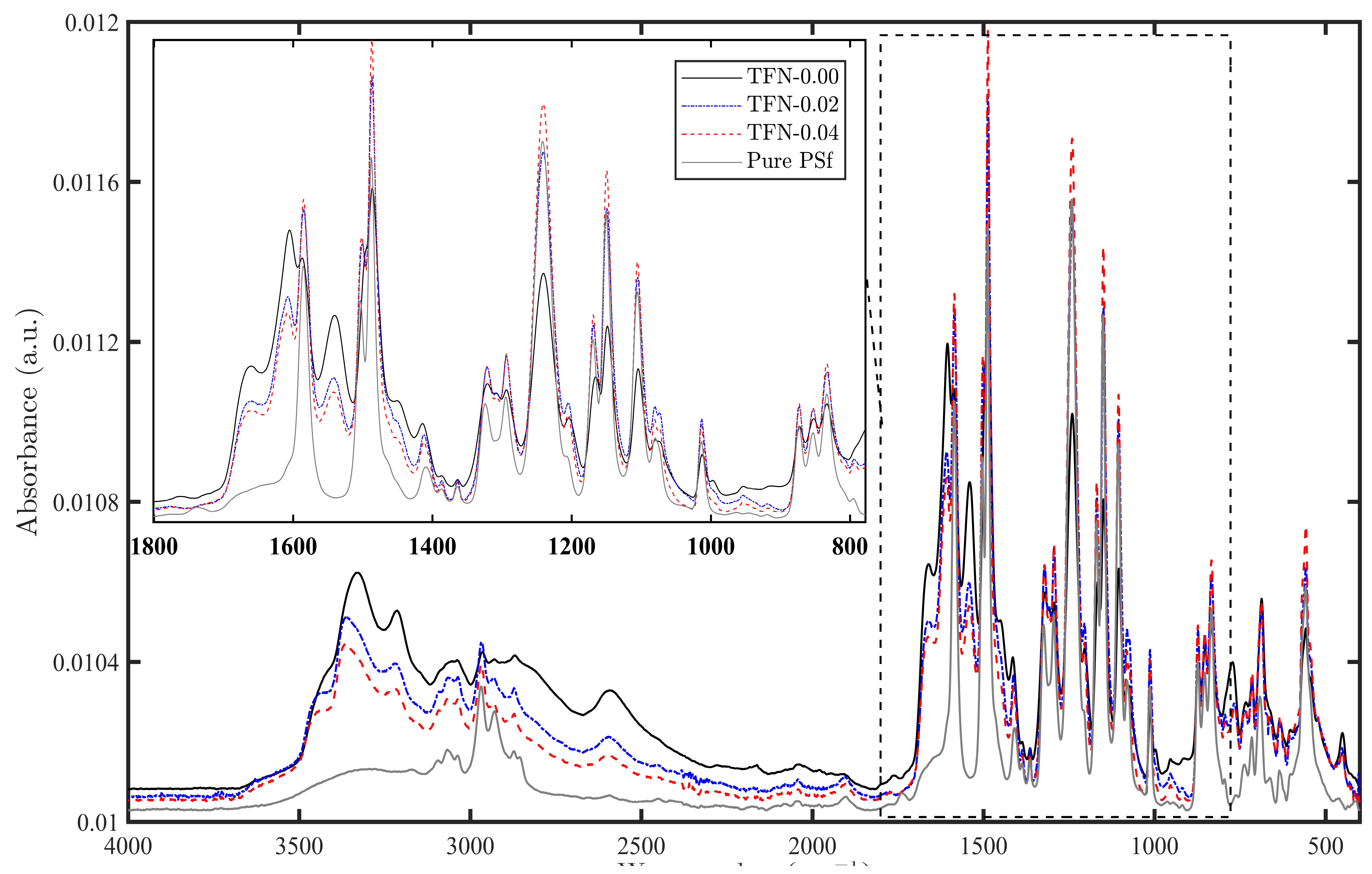

Fig. 2. ATR-FTIR spectra of PSf and PA-TFN membranes. 


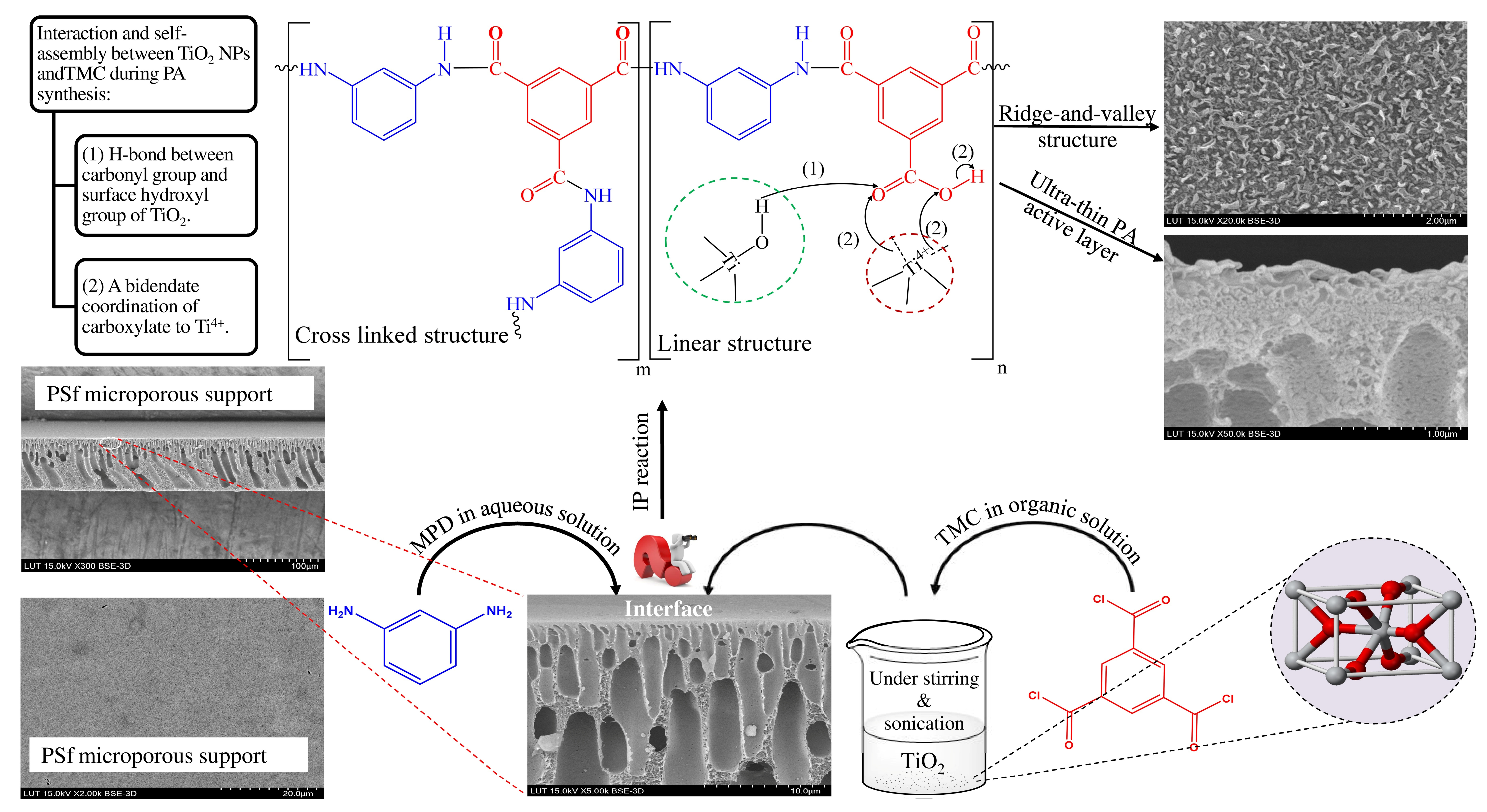

Fig. 3. Schematic of interaction and self-assembly between $\mathrm{TiO}_{2}$ nanoparticles and $\mathrm{TMC}$ during PA synthesis.

The thickness of thin PA layer of TFC and TFN membranes can be approximately determined using IR spectra according to the procedure presented by Singh et al. [62]. The procedure is fully described in Supplementary material.

\subsection{SEM analysis}

The surface morphology of nanocomposite PA film is strongly linked to the polymerization chemistry. For better discussing, the surface morphology of TFC and TFN membranes at different $\mathrm{TiO}_{2}$ loadings were monitored in two magnifications (Fig. 4). From the SEM micrographs, it can be seen that the surface characteristics were remarkably impacted in TFN membranes due to the presence of $\mathrm{TiO}_{2}$ nanoparticle in the PA coating film. It is also evidence that PA-TFC membrane is rough, having ridge and valley structure. This observed surface morphology is characteristic of MPD/TMC $[59,63]$. Additions of $\mathrm{TiO}_{2}$ nanoparticles alter the surface morphology of TFN membranes. At 0.02 $\mathrm{wt} \%$ loading, ridge and valley structure is less extended and cross-linked than the corresponding TFC membrane. By increasing $\mathrm{TiO}_{2}$ loading to $0.04 \mathrm{wt} \%$, a combination of ridge and valley, leaf-like along with nodular structure has been formed on the membrane surface. Furthermore, it is obvious 
that at such low $\mathrm{TiO}_{2}$ loadings, nanoparticles embedded in the PA layer of TFN membranes are well dispersed and not agglomerated; thus a decrease in membrane roughness is expected [22]. Since exsitu IP reaction predominantly happens at the organic side of the interface due to the relatively low solubility of most of acid chlorides in water [64], the presence of hydrophilic $\mathrm{TiO}_{2}$ in organic phase alters the rate of the polymerization reaction and final surface morphology of the TFC membranes. On the other hand, attendance of $\mathrm{TiO}_{2}$ nanoparticles might improve the miscibility of aqueous and organic phases during IP. In fact, $\mathrm{TiO}_{2}$ nanoparticles might hydrate when they are exposed to hydrated MPD. At the loadings of NPs investigated in this research, the heat of hydration is low. This might be due to the fact that as the temperature locally increased, it was rapidly vanished at the bulk of TMC solution. However, it should be also mentioned that Ostomel et al. (2006) reported the increase of the heat of hydration might locally increase up to $95{ }^{\circ} \mathrm{C}$ for LTA zeolites [65]. Although the heat of hydration is low, it might directly regulate particle kinetic energies, Brownian motion (stochastic motion of molecules and nanoparticles) and finally the miscibility of aqueous and organic phases. If the miscibility increases due to possible local rise of temperature, it can be speculated that the increase of water-organic miscibility may cause hydrolysis of acid chlorides or de-protonation of amines, thereby reducing their reactivity and the extent of cross-linking [66, 67].

As reported by Ghosh et al. [68] increasing TMC solution temperature produces thinner, rougher, more permeable films with higher hydrophilicity. Another possible explanation for the PA structure changes (e.g. the reduction in degree of cross-linking) in presence of $\mathrm{TiO}_{2}$ might be related to the high dependence of the IP reaction to the kinetics of polymerization reaction, i.e. the rate of the monomers mass transfer which directly changes the concentration of the reactive monomers in the reaction zone [69]. Adding $\mathrm{TiO}_{2}$ nanoparticles alters the thermodynamic properties (viscosity and surface tension) of the organic solution which directly influences on the solubility, diffusivity and partitioning of the MPD molecules into the reaction zone. 
The possible increase of monomer solution viscosity as a result of adding fillers is reported [22] and thus the increase of $\mathrm{TMC}$ solution viscosity in presence of $\mathrm{TiO}_{2}$ is expected. At such circumstance, both the reduction of MPD solution diffusivity due to the increase of viscosity of TMC solution [22] and possible interaction of $\mathrm{TiO}_{2} \mathrm{NPs}$ with acyl chloride of TMC restrict interfacial polymerization to fully form cross-linked PA [70]. The combination of these phenomena can be considered as a possible explanation for the formation of a less cross-linked PA film in the fabricated TFN membranes.

Furthermore, the elemental composition of membrane surfaces was measured using EDX spectroscopy and has been used in order to evaluate the degree of cross-linking. The degree of crosslinking in PA layer is usually evaluated based on the $\mathrm{O} / \mathrm{N}$ and $\mathrm{C} / \mathrm{N}$ ratios $[71,72]$. In this study, the $\mathrm{C} / \mathrm{N}$ ratio is considered due to the presence of the oxygen in the structure of $\mathrm{TiO}_{2} \mathrm{NPs}$. The PA layer possesses a linear portion $\left(\mathrm{C}_{15} \mathrm{H}_{10} \mathrm{~N}_{2} \mathrm{O}_{4}\right)$ containing a free pendant carboxylic acid group and a partially cross-linked structure, which consists of a cross-linked portion $\left(\mathrm{C}_{18} \mathrm{H}_{12} \mathrm{~N}_{3} \mathrm{O}_{3}\right)$ possessing an additional amide linkage [71]. The degree of cross-linking increases as $\mathrm{C} / \mathrm{N}$ ratio reduces regarding to the chemical structure of linear portion and cross-linked portion. The EDX technique can generally provide the bulk concentration (depth) of elements present in sample whereas XPS technique gives the elemental information present near the surface of sample. Based on the data presented in Table 3, it can be postulated that some extend of the carbon is originated from substrate layer due to the presence of sulfur from the polysulfone substrate in the EDX results. Therefore, the C/S ratio is calculated to evaluate if the originated carbon from the polysulfone substrate is the same for all prepared membranes. As can be seen, this ratio is almost constant for all membranes, indicating the fact that the $\mathrm{C} / \mathrm{N}$ ratio can reliably and qualitatively evaluate the degree of cross-linking in PA layer. The results indicate that the degree of cross-linking reduces as the concentration of $\mathrm{TiO}_{2}$ NPs increases in TMC solution, which is in line with our finding and observation in FTIR and SEM images, respectively. 
Table 3. EDX results for TFC and modified TFC Membranes with 0.02 and $0.04 \mathrm{wt} \% \mathrm{TiO}_{2} \mathrm{NPs}_{\text {. }}$

\begin{tabular}{lccc}
\hline Element & TFC or TFN 0.00 & TFN 0.02 & TFN 0.04 \\
\hline C K & 68.8 & 53.8 & 38.9 \\
N K & 13.3 & 16.6 & 16.8 \\
O K & 8.3 & 14.1 & 20.5 \\
Al K & 0.2 & 0.2 & 0.2 \\
S K & 8.8 & 6.8 & 4.9 \\
Cl K & 0.7 & 1.1 & 0.6 \\
Ti K & 0 & 7.4 & 18 \\
\hline Total & 100 & 100 & 100 \\
\hline C/N & 5.2 & 3.2 & 2.3 \\
\hline C/S & 7.8 & 7.9 & 7.9 \\
\hline
\end{tabular}

Water contact angles decrease according to TFN0.00 $(49.8 \pm 3.8)>$ TFN0.02 $(43.2 \pm 1.7)>$ TFN0.04 $(39.8 \pm 5.4)$. Thus, hydrophilicity of the pristine membrane increased by increasing the $\mathrm{TiO}_{2}$ loading which can be attributed to the superhydrophilic nature of $\mathrm{TiO}_{2}$ and its role during IP process which was discussed above. As $\mathrm{TiO}_{2}$ nanoparticles incorporates into PA structure, the cross-linking and more un-reacted carboxylic acid groups of TMC, giving hydrophilicity in the membrane, are exposed at the surface of TFN membrane [22]. Higher loading of $\mathrm{TiO}_{2}$ leads to lower cross-linking of polyamide structure, less dense matrix, more open membrane and finally more hydrophilicity of membrane surface. 

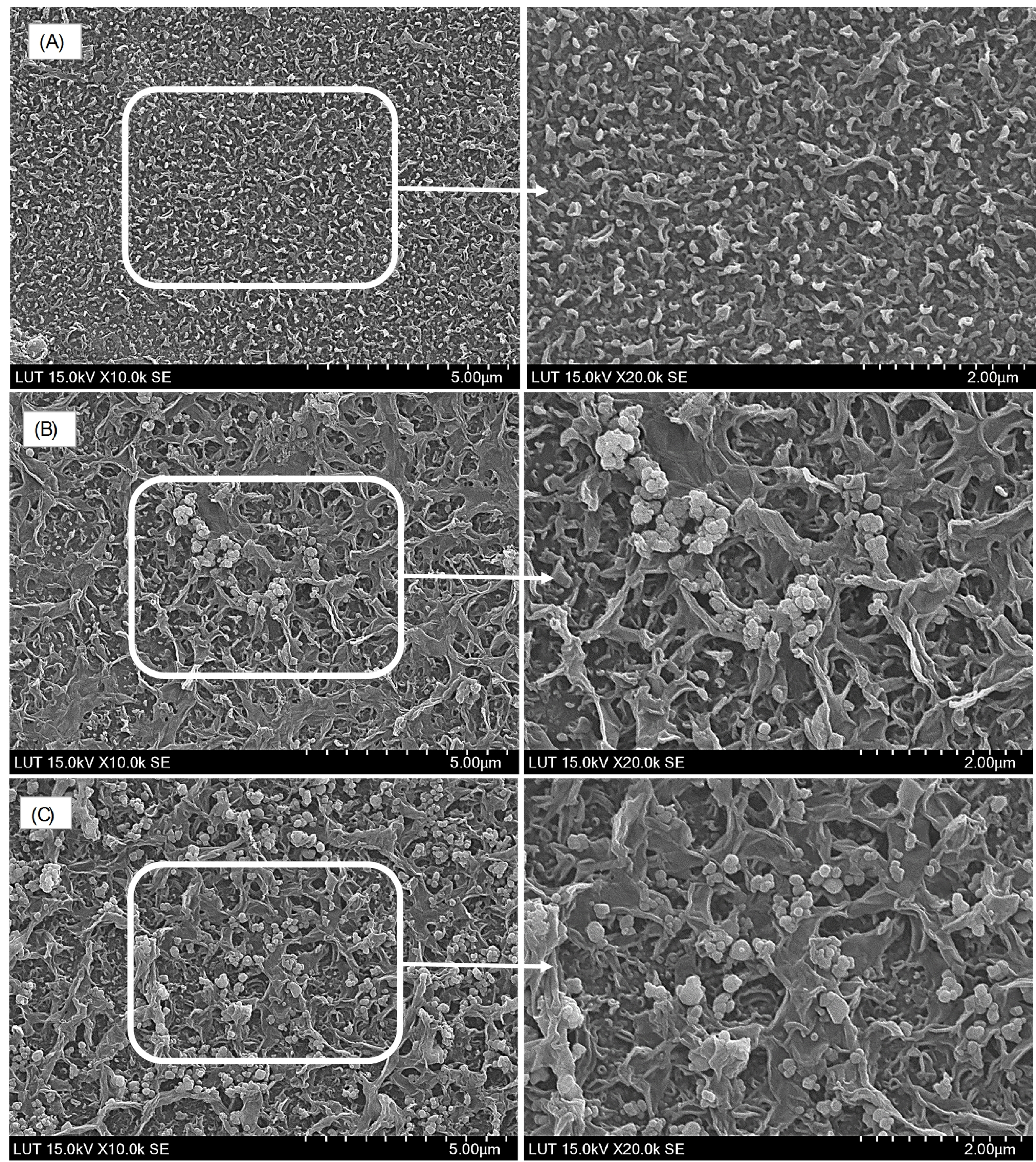

Fig. 4. SEM surface morphology of PA membranes (A) TFN0.00, (B) TFN0.02 and (C) TFN0.04.

\subsection{AFM analysis}

Fig. 5 illustrates three dimensional (3D) AFM images of surface [ $5 \mu m \times 5 \mu m$ frame] of the prepared membranes. Additionally, the results of statistical analysis including to the maximum height of peak $\left(R_{p}\right)$, the maximum depth of valley $\left(R_{v}\right)$, the average arithmetic roughness $\left(R_{a}\right)$, and the root 
mean square roughness ( $\mathrm{R}_{\mathrm{q}}$ or RMS) for the TFC and TFN membranes are summarized in Table 4. By incorporating $\mathrm{TiO}_{2} \mathrm{NPs}$, the PA structure is altered from "ridge and valley" (TFC membrane) to "ridge and valley-nodular" and finally completely "nodular" structures. At low dosages (TFN0.02), NPs embedded in the PA layer of nanocomposite membranes are not agglomerated; thus, a decrease in roughness is observed. However, the partial aggregation of $\mathrm{TiO}_{2} \mathrm{NPs}$ at higher dosages (TFN0.04 and TFN0.1) lead to the higher RMS values. Similarly, Namvar-Mahboub et al. [22] showed that the microstructure morphologies of TFN membranes were changed by the addition of UZM- 5 to the PA layer and a smoother surface was obtained at lower content.

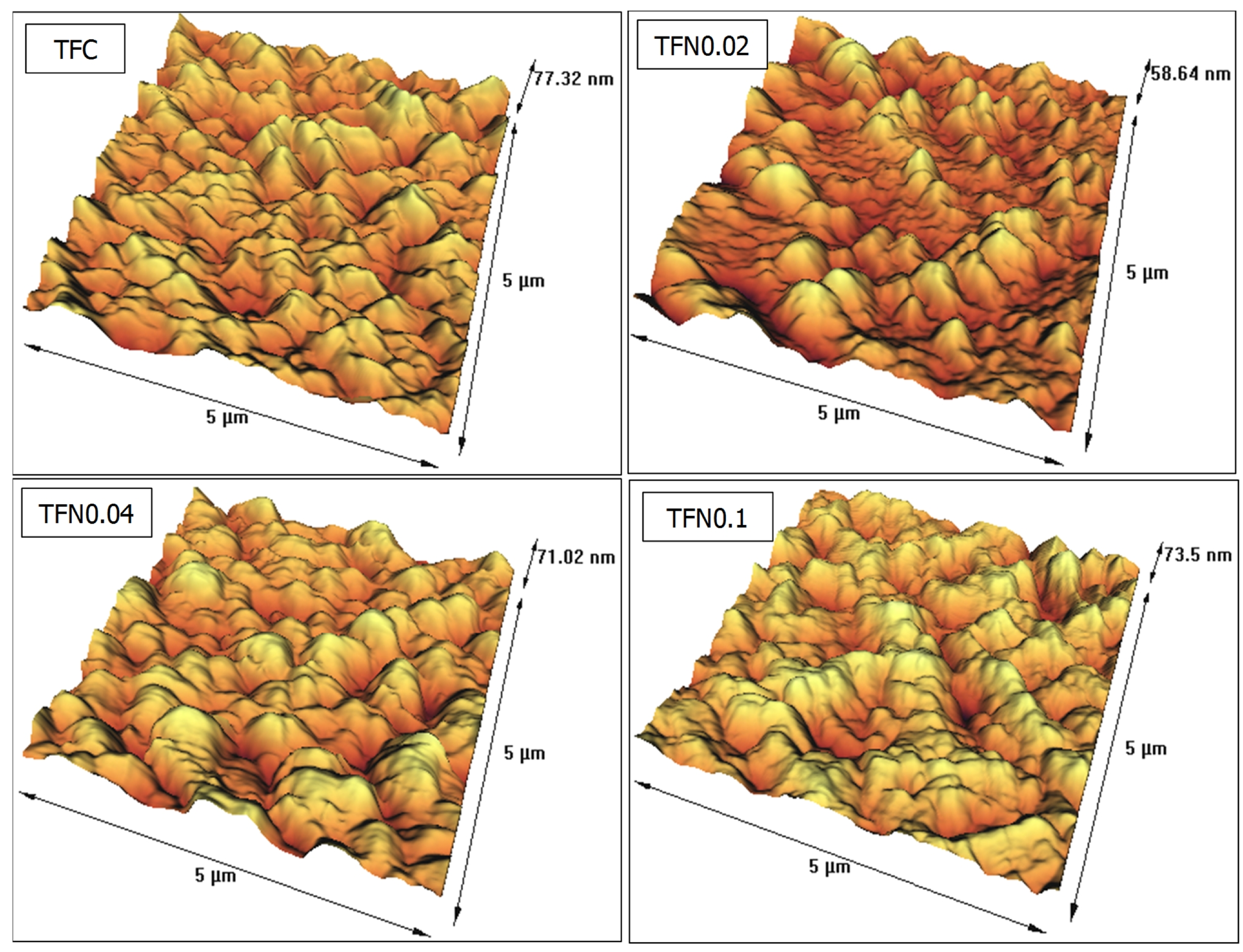

Fig. 5. AFM images of TFC and TFN membranes. 
Table 4. Surface roughness parameters of TFC and TFN membranes.

\begin{tabular}{lcccc}
\hline Sample & $\mathrm{R}_{\mathrm{a}}(\mathrm{nm})$ & $\mathrm{R}_{\mathrm{q}}(\mathrm{nm})$ & $\mathrm{R}_{\mathrm{v}}(\mathrm{nm})$ & $\mathrm{R}_{\mathrm{p}}(\mathrm{nm})$ \\
\hline TFC & 10.31 & 12.83 & -42.85 & 39.81 \\
TFN0.02 & 8.94 & 11.31 & -47.56 & 21.62 \\
TFN0.04 & 10.68 & 13.62 & -48.43 & 42.47 \\
TFN0.1 & 12.61 & 15.39 & -54.26 & 47.73 \\
\hline
\end{tabular}

\subsection{Real content of NPs in PA layer}

In this study sodium hypochlorite was used to dissolve PA layer and to release $\mathrm{TiO}_{2}$ nanoparticles. The results showed that $\mathrm{NaOCl}$ degraded successfully PA layer, resulting in average salt rejections below 4\%. For further support, visual inspection with SEM was used to con firm the successful removal of the active layer. For instance, the SEM pictures of the surface of TFN0.04 membranes before (A) and after (B) the chlorine conversion treatment $(300,000 \mathrm{ppm} \cdot \mathrm{h})$ are shown in Fig. 6. Based on this qualitative assessment, the PA active layer has undergone significant changes in its morphology. Thus, it is suggested that the conversion process results in substantial and possibly complete removal of the PA layer from the underlying membrane support layers.

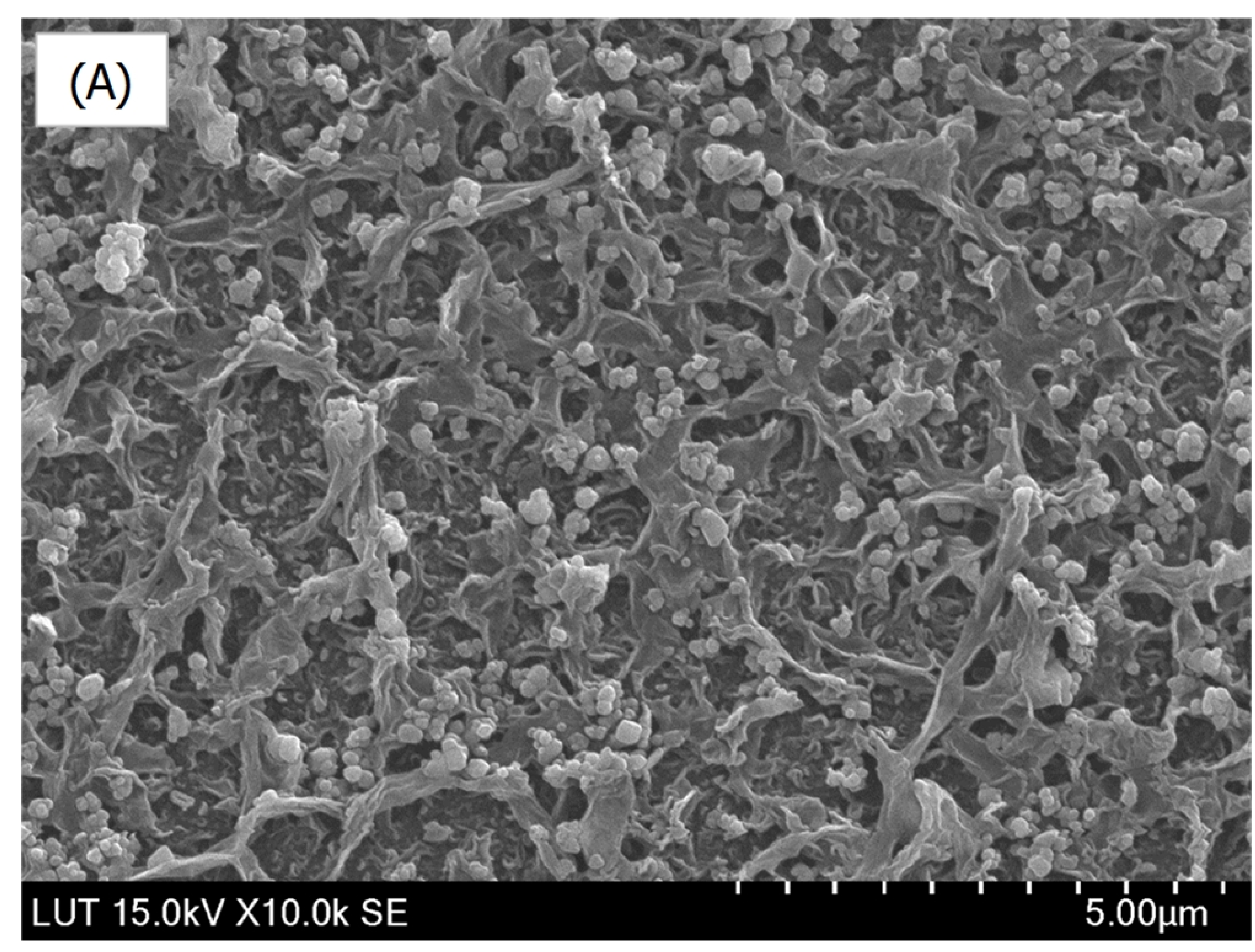

\section{(B)}

Fig. 6. SEM images of TFN0.04 membranes before (A) and after (B) chlorine exposure.

Finally, the concentration of $\mathrm{TiO}_{2}$ in aqueous media has been measured by ICP-OES. Table 5 shows the real content of $\mathrm{TiO}_{2}$ nanoparticles in TMC solution and PA layer. As can be observed, a small fraction of $\mathrm{TiO}_{2}$ are incorporated into the PA layer. 
Table 5. Real content of $\mathrm{TiO}_{2}$ nanoparticle in $\mathrm{TMC}$ solution and $\mathrm{PA}$ layer

\begin{tabular}{lcc}
\hline \multirow{2}{*}{ Real content of $\mathrm{TiO}_{2}$} & \multicolumn{2}{c}{ TFN Membrane Type } \\
\cline { 2 - 3 } & TFN 0.02 & TFN 0.04 \\
\hline In TMC solution $(\mathrm{mg})$ & 3.3 & 6.6 \\
In PA layer $(\mathrm{mg})$ & $0.203 \pm 0.013$ & $0.480 \pm 0.012$ \\
In PA layer (mg/m²) & $103 \pm 5$ & $244 \pm 6$ \\
\hline
\end{tabular}

\subsection{Nanoparticle leaching test}

Three membrane samples with high loading of $\mathrm{TiO}_{2}$ NPs in PA layer (TFN0.04) were prepared and

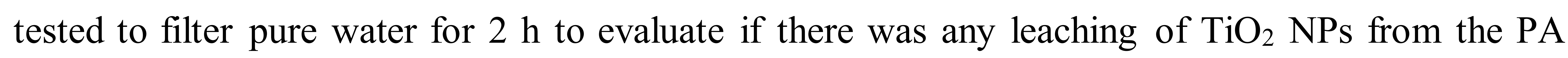
nanocomposite layer to feed or permeate samples. The presence of NPs in the solutions was detected by ICP-EOS with respect to titanium element. As results in Table 6 show some leaching of titanium occurred. By taking into account the membrane area and volumes of permeate and concentrate streams it can be calculated that less than $6 \%$ of titanium was leached during $2 \mathrm{~h}$ of filtration.

Ti leaching might be the result of poor interaction of nanofillers with the PA layer during interfacial polymerization (especially those exposed at the membrane surface), making them unable to be embedded firmly within the PA matrix.

Table 6. Ti element detected (released) in feed and permeate samples of TFN0.04 during $2 \mathrm{~h}$ filtration test

\begin{tabular}{lccc}
\hline \multirow{2}{*}{ Ti concentration after 2 $\mathrm{h}$ in } & \multicolumn{3}{c}{ TFN0.04 } \\
\cline { 2 - 4 } & Sample 1 & Sample 2 & Sample 3 \\
\hline Feed $(\mathrm{ppb})$ & 14 & 11 & 15 \\
Permeate $(\mathrm{ppb})$ & 9 & 5 & 12 \\
\hline
\end{tabular}

Compared to the other nanometal oxides, nano- $\mathrm{TiO}_{2}$ is one of the least cytotoxic [73], thus it's minor release might not be a substantial risk compared to the other NPs. In addition, $\mathrm{TiO}_{2}$ is commonly utilized in sunscreens, cosmetics, and self-cleaning coatings for its antimicrobial properties [74]. It's application in pharmaceuticals, pigments, food additives, and solar cells has also been reported in different studies $[74,75]$. 


\subsection{Surface charge analysis}

The $\mathrm{pH}$ of feed sample is prominent factor in aqueous media affecting the surface charge of the membrane. Accordingly, zeta potential versus $\mathrm{pH}$ for membrane samples performed in the presence of $0.001 \mathrm{M} \mathrm{KCl}$ aqueous solution are illustrated in Fig. 7. As can be seen, a few generalizations can be made regarding the TFN membranes. First of all, zeta potential is positive at low $\mathrm{pH}$ and negative at high $\mathrm{pH}$ values. In other words, the surface of membranes possesses negatively charge over the $\mathrm{pH}$ range of 4-8. More specifically, all the membranes were generally found to have a far-ranging negative surface charge. Secondly, the shape of the zeta potential curves is indicative of typical amphoteric surfaces. Since the TFC membranes are made by the IP reaction of polyfunctional amine and acyl chloride monomers, ionizable carboxyl and amine functional groups may be expected on the membrane surface. Thus, the positive and negative charges contributed by the residue amine and carboxyl groups, respectively. The carboxyl groups generated from hydrolysis of acyl chloride groups. Meanwhile, as explained in FTIR section and shown in Fig. 3, $\mathrm{TiO}_{2}$ nanoparticles have a tendency to bind to the carboxylic groups in linear structure part of PA. Consequently, less negative zeta potential values were measured after $\mathrm{TiO}_{2}$ was introduced. Thirdly, there may be a point where the plot passes through zero zeta potential. This point is called isoelectric point (IEP) and is very important from a practical consideration. The shift of the IEP a little bit from $\mathrm{pH} 3.8$ for the TFN0.00 surface to $\mathrm{pH} 3.5$ for the TFN0.04 layer confirms the presence of the $\mathrm{Ti}^{4+}$ nanoparticles on the surface. These trends are consistent with that of TFC membranes reported in other studies [56,76-78].

In conclusion, $\mathrm{TiO}_{2}$ appears to have a minimal effect on the zeta potential, making it slightly less negative. In other words, due to the low loading of $\mathrm{TiO}_{2}$, only trace reduction was observed in membrane surface charge. Generally, membrane surface with zeta potential close to zero exhibits good antifouling properties with regards to charge organic foulants because the interaction between charged surface and organic foulants is impaired [78]. Therefore, it can be expected that incorporation or deposition of $\mathrm{TiO}_{2}$ nanoparticles on a PA layer improves the separation of sulfur compounds. 


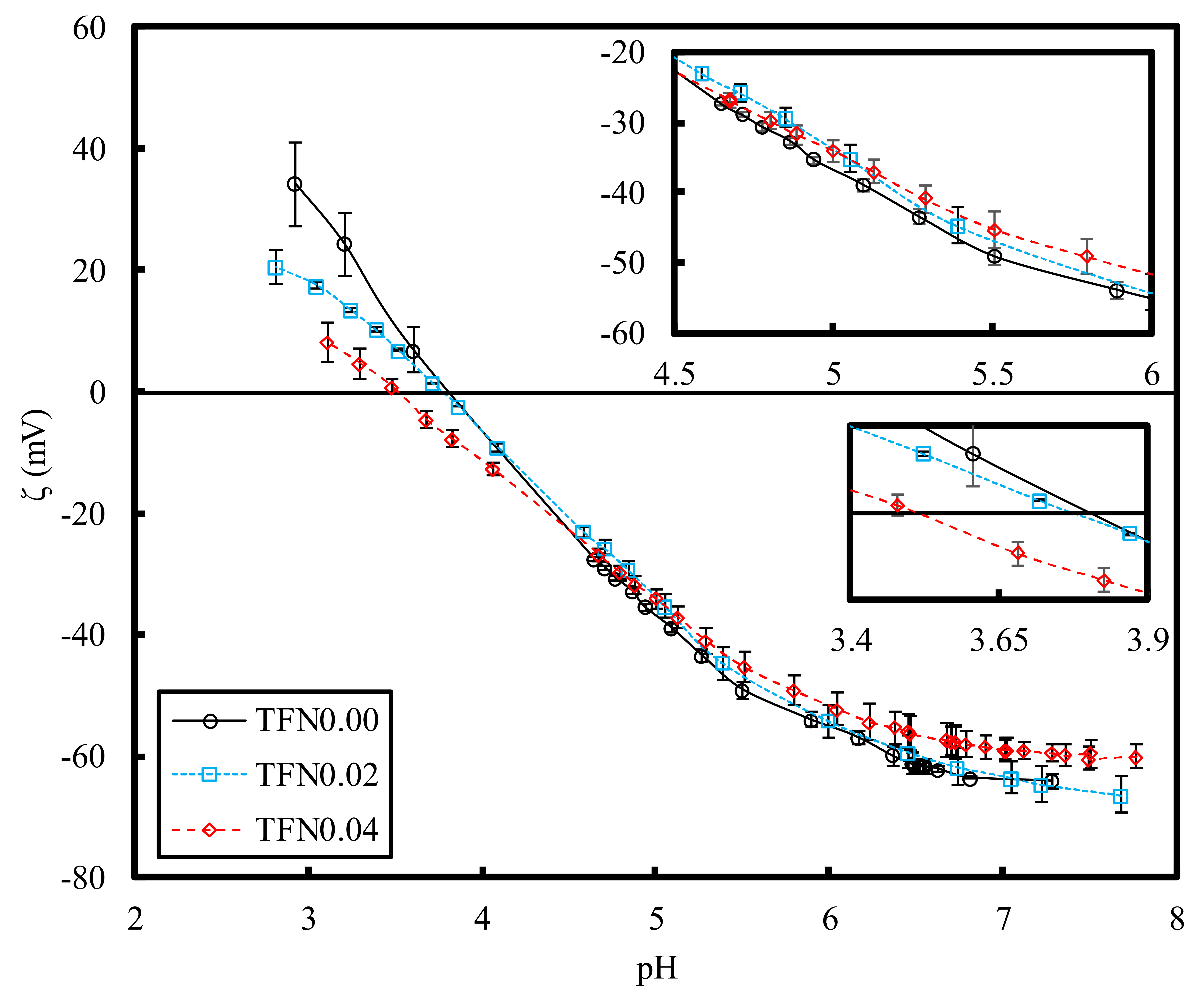

Fig. 7. The variation of zeta potential versus $\mathrm{pH}$ for TFN membranes.

\subsection{Analysis of variance}

ANOVA table is used for understanding the importance of each term in the regression model, such as checking the model importance, the individual model coefficients, and the lack-of-fit (LOF). Definitions for each statistic parameter in ANOVA table is provided by details elsewhere [34,50]. All the statistic information for SPF and SRE were computed from the analysis of variance summarized in Tables 7 and 8, respectively. The ANOVA tables are entirely built on the premise that the factors are fixed, not random and the design is crossed, not nested. Regarding these tables, the model Fvalues for the SPF and SRE were 111.37 and 312.31, respectively. These values indicate that the models are statistically significant, and there is only less than $0.01 \%$ chance that these levels-of-fi $t$ can occur due to random chance and noise $[50,79,80]$. P-values less than 0.05 indicate that the model terms are significant. Hence, all the main effects in the case of SPF, A, B and C, and also the 2FIs effects between $\mathrm{AB}$ and $\mathrm{AC}$ were significant within the levels and experimental conditions. 
Regarding SRE, not only all the main effects, but also all 2FIs were significant within the levels in experimental conditions. Furthermore, to avoid unnecessary screen clutter, high-order interactions were ignored by default. The effect hierarchy principle illustrates that lower order effects are more important than higher order ones. Using this principle, one may be able to focus on main effects and 2FIs, and also assume that the higher order interactions are negligible [81]. The LOF will be significant ( $p$-value $<0.05$ ) if the model does not fit the data satisfactorily. The LOF F-values of 0.2466 and 0.8961 indicate that it is insignificant ( $p$-value $>0.1$ ) for both of the responses (not significant LOF is good) associated with the pure error, thus the eliminated terms are absolutely unimportant for the models [82].

Coefficient of determination $\left(R^{2}\right)$ is a measure of the amount of variation around the mean explained by the model. It is proposed that $R^{2}$ should be close to 1 for a good fit model [83]. As it is shown in Tables 7 and 8, the predicted models for each response have a suitable $R^{2}$ value. Adjusted coefficient of determination $\left(R_{A d j}^{2}\right)$ is defined as a measure of the amount of variation around the mean explained by the model, adjusted for the number of terms in the model. Tables 7 and 8 showed that the $R^{2}$ and $R_{A d j}^{2}$ values for both models do not differ considerably. Predicted coefficient of determination ( $R_{\text {Pred }}^{2}$ ) measures the amount of variation in the new data explained by the model. The $R_{\mathrm{Pred}}^{2}$ values are close to the values of $R_{A d j}^{2}$. A rule of thumb is that the adjusted and predicted- $R^{2}$ values should be within 0.2 of one another. Adequate precision measures the signal to noise ratio. The values greater than 4 are desirable to indicate adequate model discrimination [37]. The values of this statistical parameter are well above 4 for both responses. Coefficient of variation (C.V.\%) is the standard deviation expressed as a percentage of the mean and is calculated by dividing the standard deviation by the mean value and multiplying by 100 . As a general rule, it should not be greater than $10 \%$ for a good fit to the selected model [83]. It is less than $10 \%$ for both responses. Eventually, the final 
regression empirical models based on the main effects and 2FIs, which are performed on SPF $\left(y_{l}\right)$ and $\operatorname{SRE}\left(y_{2}\right)$ of TFN membrane with coded variables, are as follows:

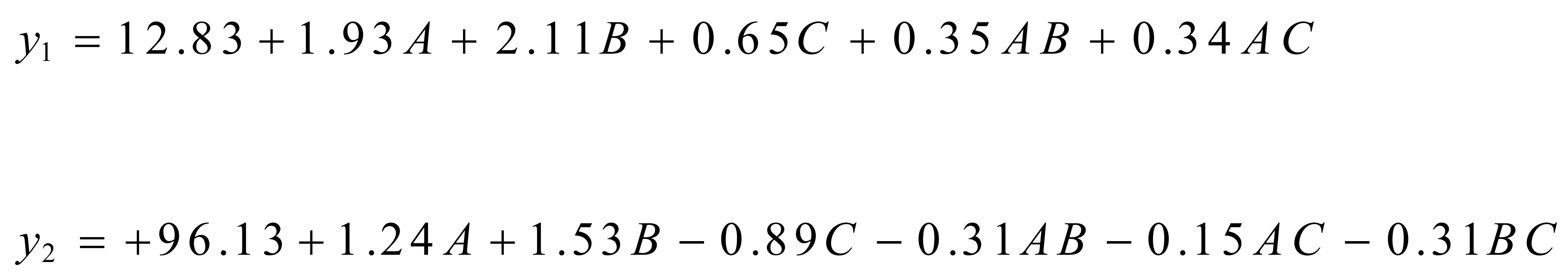

Table 7. ANOVA for selected SPF model.

\begin{tabular}{lcccccc}
\hline Source & SS & DF & MS & F value & $\begin{array}{c}\text { p-value } \\
\text { "Prob }>\text { F" }\end{array}$ & \\
\hline Model & 87.89 & 5 & 17.58 & 111.37 & $<0.0001$ & significant \\
A-[TiO 2$]$ & 37.36 & 1 & 37.36 & 236.73 & $<0.0001$ & \\
B-Pressure & 44.44 & 1 & 44.44 & 281.54 & $<0.0001$ & \\
C-Temperature & 4.20 & 1 & 4.20 & 26.60 & 0.0003 & \\
AB & 0.97 & 1 & 0.97 & 6.12 & 0.0309 & \\
AC & 0.92 & 1 & 0.92 & 5.86 & 0.034 & \\
Residual & 1.74 & 11 & 0.16 & & & not significant \\
Lack of Fit & 1.63 & 9 & 0.18 & 3.42 & 0.2466 & \\
Pure Error & 0.11 & 2 & 0.053 & & & \\
Cor Total & 89.63 & 16 & & & & \\
Std. Dev. & 0.40 & & $R^{2}$ & & \\
Mean & 12.83 & Adjusted- $R^{2}$ & 0.9806 & & \\
C.V. \% & 3.10 & \multicolumn{7}{c}{ Predicted- $R^{2}$} & 0.9222 & & \\
PRESS & 6.98 & Adequate precision & 39.733 & & \\
\hline
\end{tabular}

Table 8. ANOVA for selected SRE model.

\begin{tabular}{lcccccc}
\hline Source & SS & DF & MS & F value & $\begin{array}{c}\text { p-value } \\
\text { "Prob }>\text { F" }\end{array}$ & \\
\hline Model & 48.23 & 6 & 8.04 & 312.31 & $<0.0001$ & significant \\
A-[TiO 2$]$ & 15.25 & 1 & 15.25 & 592.61 & $<0.0001$ & \\
B-Pressure & 23.35 & 1 & 23.35 & 907.16 & $<0.0001$ & \\
C-Temperature & 7.94 & 1 & 7.94 & 308.45 & $<0.0001$ & \\
AB & 0.76 & 1 & 0.76 & 29.63 & 0.0003 & \\
AC & 0.18 & 1 & 0.18 & 6.88 & 0.0255 & \\
BC & 0.75 & 1 & 0.75 & 29.15 & 0.0003 & \\
Residual & 0.26 & 10 & 0.026 & & & \\
Lack of Fit & 0.15 & 8 & 0.018 & 0.33 & 0.8961 & not significant \\
Pure Error & 0.11 & 2 & 0.056 & & & \\
Cor Total & 48.49 & 16 & & & & \\
\hline Std. Dev. & 0.16 & \multicolumn{7}{c}{$R^{2}$} & 0.9947 & & \\
Mean & 96.13 & Adjusted- $R^{2}$ & 0.9915 & & \\
C.V. \% & 0.17 & \multicolumn{7}{c}{ Predicted- $R^{2}$} & 0.9878 & & \\
PRESS & 0.59 & Adequate precision & 70.99 & & \\
\hline
\end{tabular}


At the end of this section, three assumptions should be checked. At the outset, in all experiments through the completely randomized experimental design, the factors have to be reserved at a fixed level. In the second place, the errors are normally distributed in the design. As a final point, for each treatment or factor level, the observations are independently distributed within the identical variance [34]. Basically, the plots of studentized form of residuals should be examined, which show you how well the model satisfies the assumptions of the analysis of variance. In this regards, normal percentage probability plot of the studentized residuals and the plots of the studentized residuals versus different independent variables, particularly the predicted response values attained from the model were checked, provided and fully described in Supplementary material. Although all figures presented a nearly constant variance and random scatters over the variable ranges, there was no reason to suspect any violation of the independence or constant variance assumption. Thus, all plots appeared satisfying and there was no exclusive trend to demolish the analysis.

\subsection{Effect of input variables on SPF and SRE}

In order to obtain a better apprehending of the results and compare values across the treatment combination of experimental runs, two-dimensional (2D) clustered columns and contour line maps of the experimental and predicted results are plotted in Fig. 8. As can be observed, the predicted values were in reasonable agreement with the experimental data, further confirming the high predictive power of the model in the range of experimental values considered for the factors [79]. This incident can also be confirmed by the predicted- $\mathrm{R}^{2}$ values for SPF and SRE in Tables 7 and 8 , respectively. Contour line maps also demonstrate the mutual effect of each two input variables on permeate flux and rejection factor while the last input variable was held constant at its center point. It should be noted that other contour line maps at low and high levels of last input variable were illustrated in Supplementary material.

As was pointed out in the introduction to this paper, the generalizability of the results is subjected to certain limitations, such as concentration polarization and various types of fouling. Accordingly, the 
decline in permeate flux across the membrane after a specific period of time is one of the most important challenges in wastewater treatment system. The ex-situ IP reaction may produce the confinement of $\mathrm{TiO}_{2}$ nanoparticles on both the surface and inside the PA membrane. As a result, TFN membranes containing $\mathrm{TiO}_{2}$ nanoparticles in the PA coating fi $\mathrm{lm}$ were more hydrophilic, smooth, and permeable than the baseline TFC membrane with approximately similar negatively charged surface. The maximum SPF value in the design space is equal to $17.66 \mathrm{LMH}$ and observed at high levels of input variables. In other words, SPF increased by increasing $\mathrm{TiO}_{2}$ nanoparticle concentration, TMP and operating temperature. This phenomenon is similar to theoretical prediction [84]. These facts should be taken into account that adding $\mathrm{TiO}_{2}$ nanoparticles leads to increase of water uptake in the membranes, which comes from the increase of membrane hydrophilicity as supported by contact angle values. Furthermore, the surface morphology of TFC membranes can be altered by adding $\mathrm{TiO}_{2}$ nanoparticles and the intensity of concentration polarization, fouling as well as formation of organic foulants on the surface of the membrane was markedly influenced by membrane surface morphology $[85,86]$. If the IP process is appropriately progressed without any limitations, the selective PA layer of TFC membrane will maintain the typical ridge-and-valley structure. The presence of nanoparticles partly changes the continuity of the PA layer of TFC to the nodular structure along with ridge and valley and thus combination of both structures formed on the support surface as was observed in SEM micrographs. Consequently, $\mathrm{TiO}_{2}$ opened pores and created a new pathway for permeation of solvent through TFN membrane [22,87]. Regarding contour line maps, with increasing effective feed pressure, the SPF raised. This correlation is related to the fact that in pressure driven membrane separation processes (i.e. NF), the diffusion potential of components through membrane generally increases by increasing TMP. Also, permeate flux increased linearly with pressure indicating that membrane compaction effects were negligible in the pressure employed in the design space [88]. The increase of SPF by increasing the temperature is probably because of three main reasons. First of all, the rise in temperature decreases feed viscosity. Secondly, water permeability (self-diffusivity) and also mass transfer coefficient increase by 
increasing temperature [89]. The last reason is that temperature directly regulates kinetic energies, Brownian motion of particles (solvent and solutes) in the feed and finally the concentration polarization. Hence, if the kinetic energy of the particles (especially solutes) is higher than their interaction potential, coagulation of two particles will not occur after collision. Consequently, the probability of the formation of concentration polarization layer and fouling phenomenon can be decreased by increasing temperature.

Fig. 8 also exhibits the effect of noted parameters on SRE. Typically, there is an inherent trade-off relationship between flux and rejection in membrane separation processes. However, this trend cannot be seen in this figure. As an example, at the low level of operating pressure and temperature, SRE increased from $93.48 \%$ for TFC membrane to $96.88 \%$ for $\mathrm{TFN}$ containing $0.04 \% \mathrm{TiO}_{2}$ while simultaneously an increase of approximately $30 \%$ in permeate flux was achieved. A possible explanation for this behaviour might be that the PA layer will still be formed by the incorporation of $\mathrm{TiO}_{2}$ nanoparticles at low concentrations $(0.02-0.04 \%)$. At these loading, ridge and valley structure is less extended and cross-linked when compared to TFC membrane. These observations are consistent with various researchers' findings [22,90,91]. Another possible explanation for this is that the water mass transfer characteristics of the film were increased by incorporation of $\mathrm{TiO}_{2}$ nanoparticles coating, while there was no significant difference in solute mass transfer. In other words, the ratio of solvent to solute transport rate across the membrane increases by increasing hydrophilicity and fouling resistant [86]. It is also obvious from this figure that SRE increased by increasing TMP. This phenomenon is occurred due to the adsorption of solute compounds on the surface of the membrane at higher applied pressure [92]. On the other hand, NF is a pressure-driven membrane separation process in which operating pressure has a positive effect on the passage of water and other components through the membrane. However, by increasing the TMP, the water transport rate is relatively higher than sulfur compounds due to its lower kinetic and hydrodynamic diameter which leads to the rejection increase [22]. The level of solute retention was found to decrease when the temperature increases. The maximum and minimum retention of sulfur compounds at low and 
high temperature were nearly $99 \%$ and $94 \%$, respectively. This phenomenon is due to a higher diffusion rate of solute through the membrane. At higher temperatures, the PA NF membrane network pores is partially swelled, allowing a greater amount of the solute to pass. Furthermore, the concentration polarization and membrane fouling decreased (especially at low TMP) with the increase in feed temperature due to the change in density and viscosity of the solution $[48,93]$. 

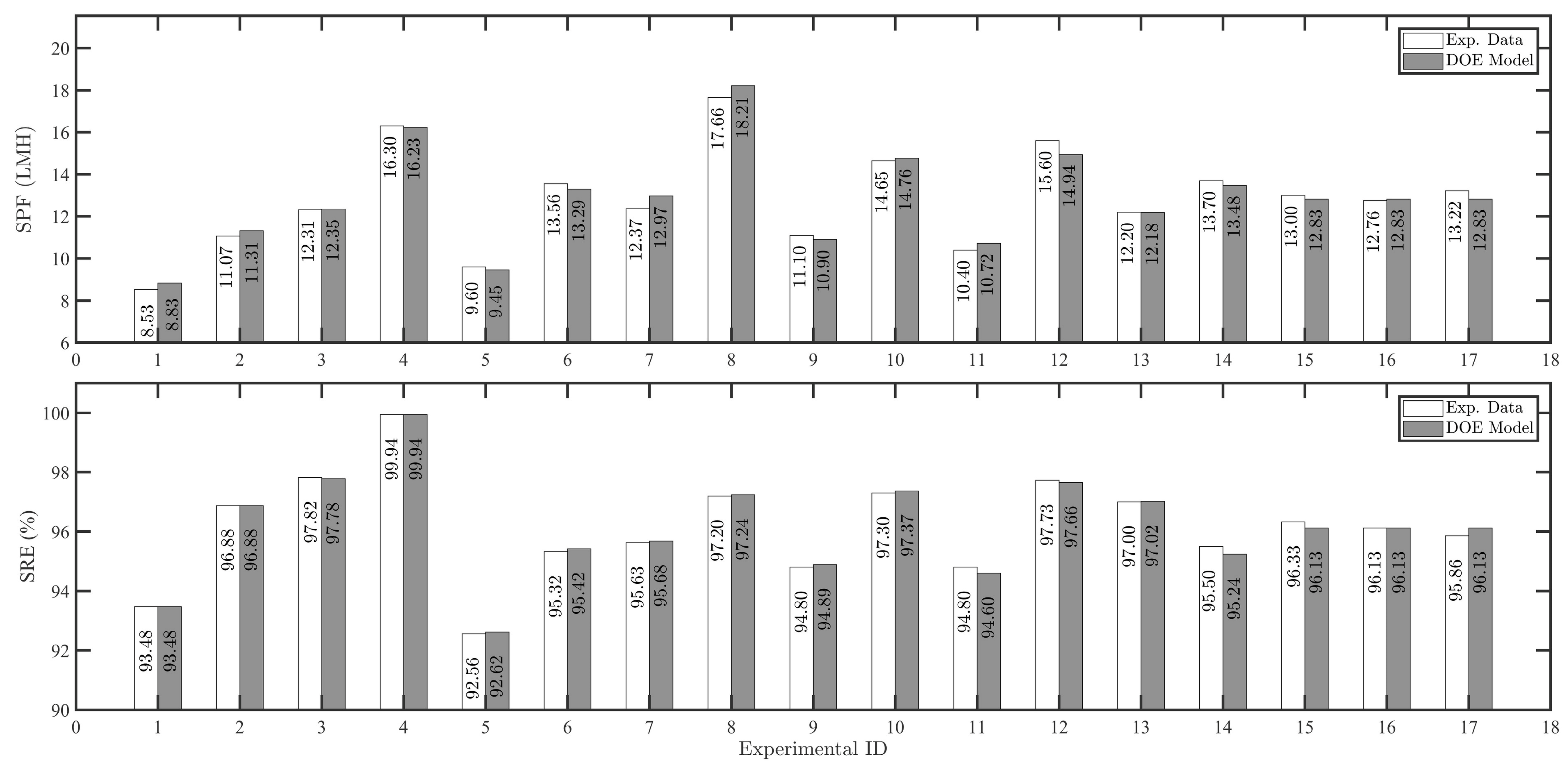

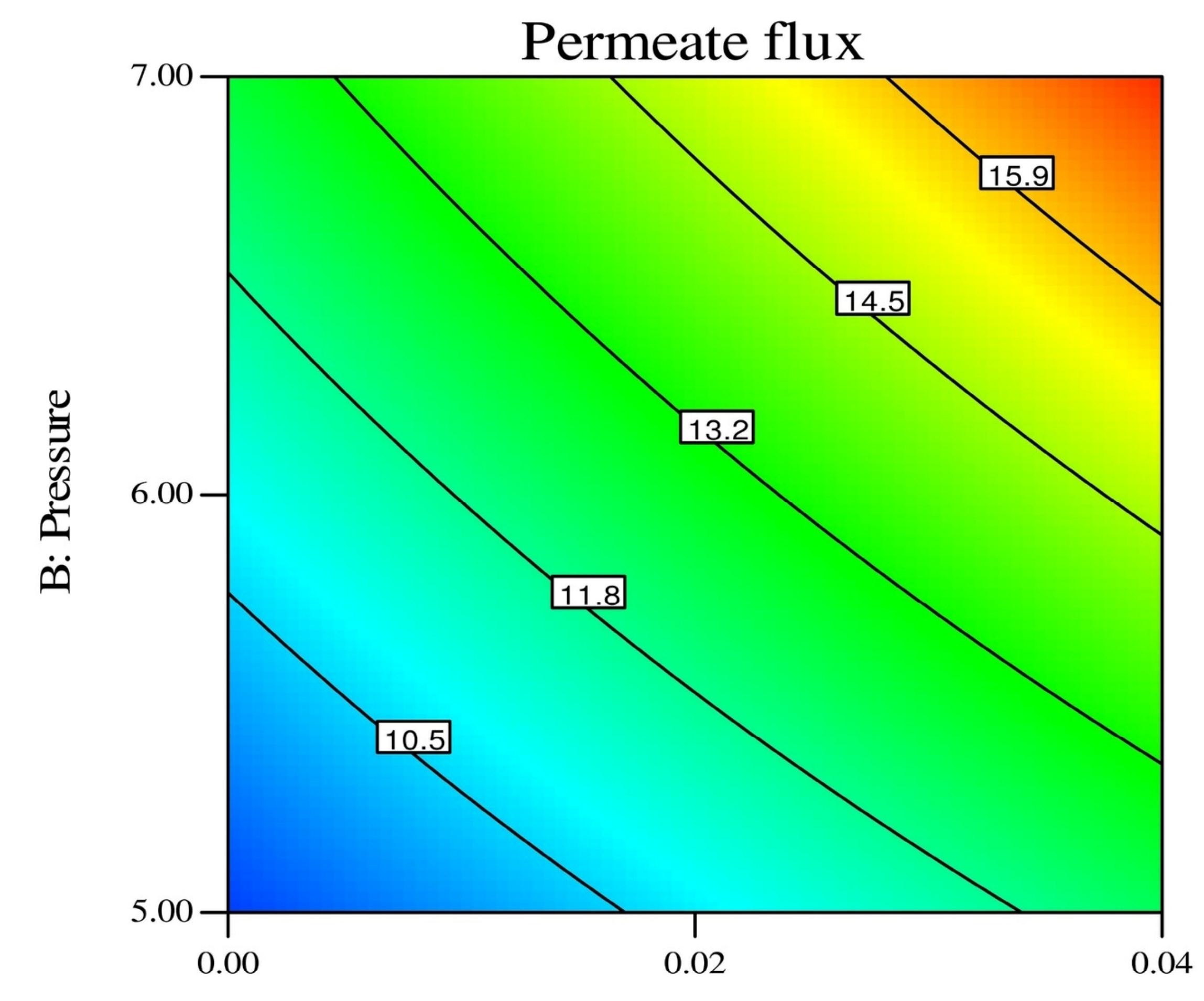

A: [TiO2]

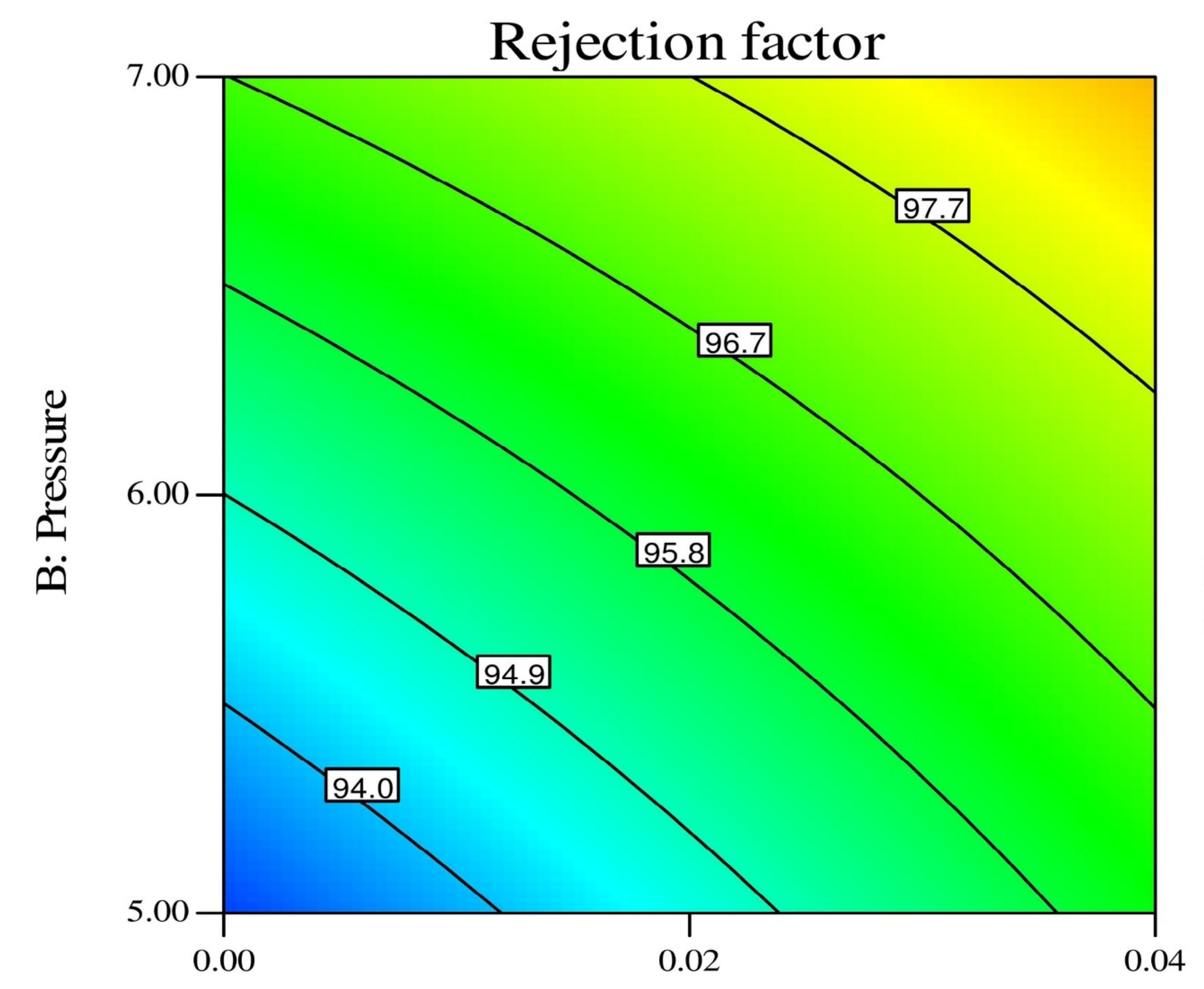

A: [TiO2]

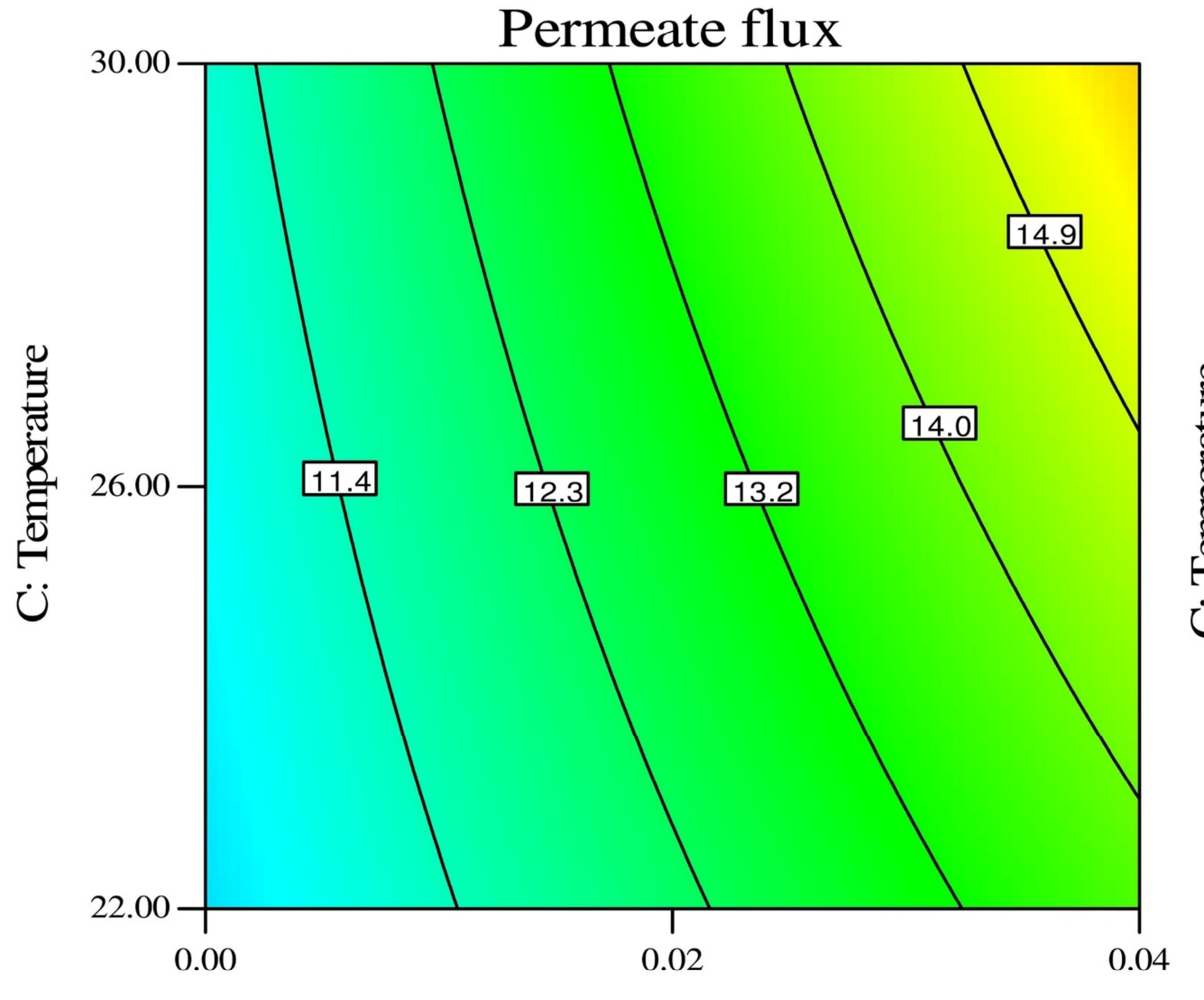

A: [TiO2]

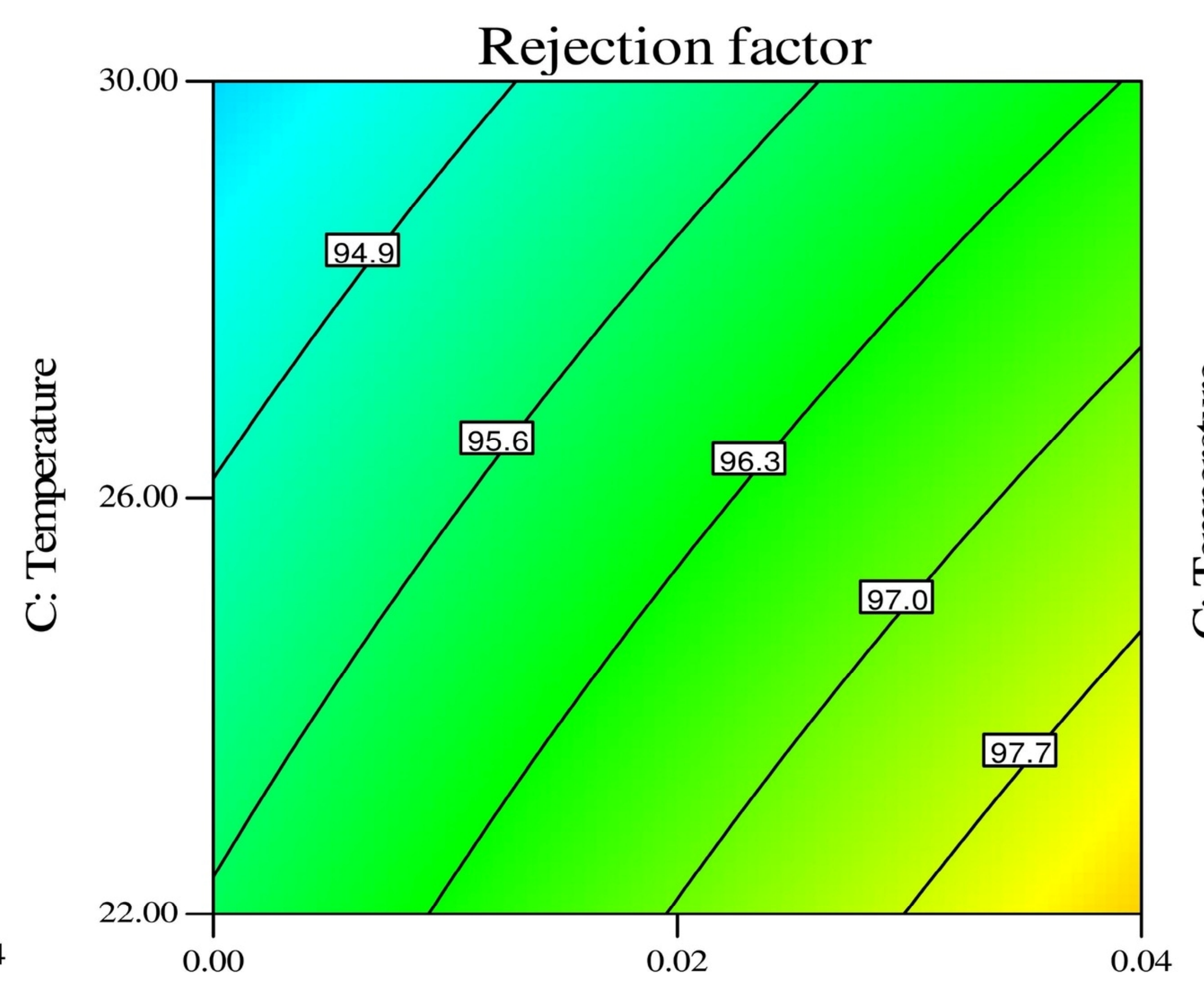

A: [TiO2]

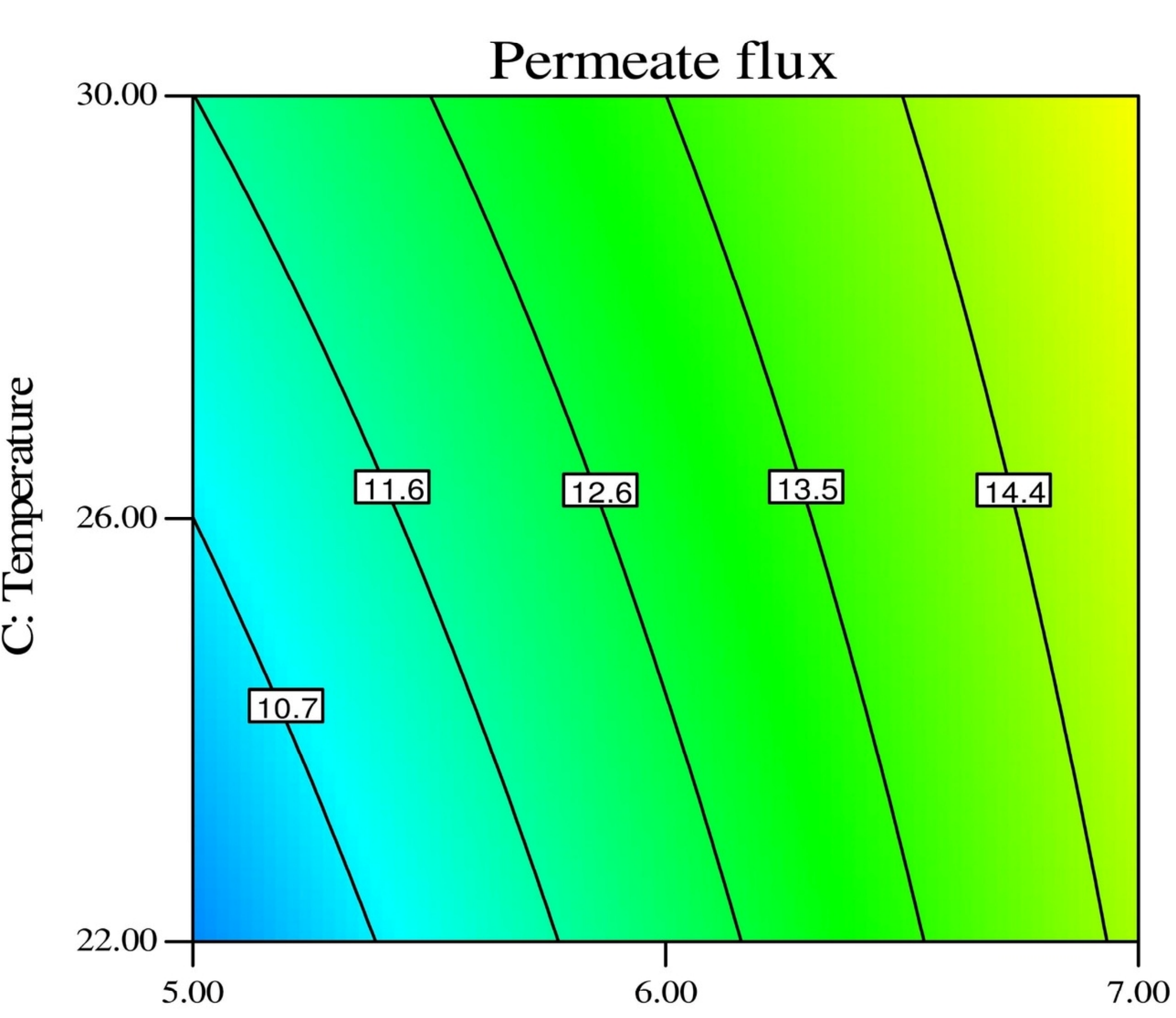

B: Pressure

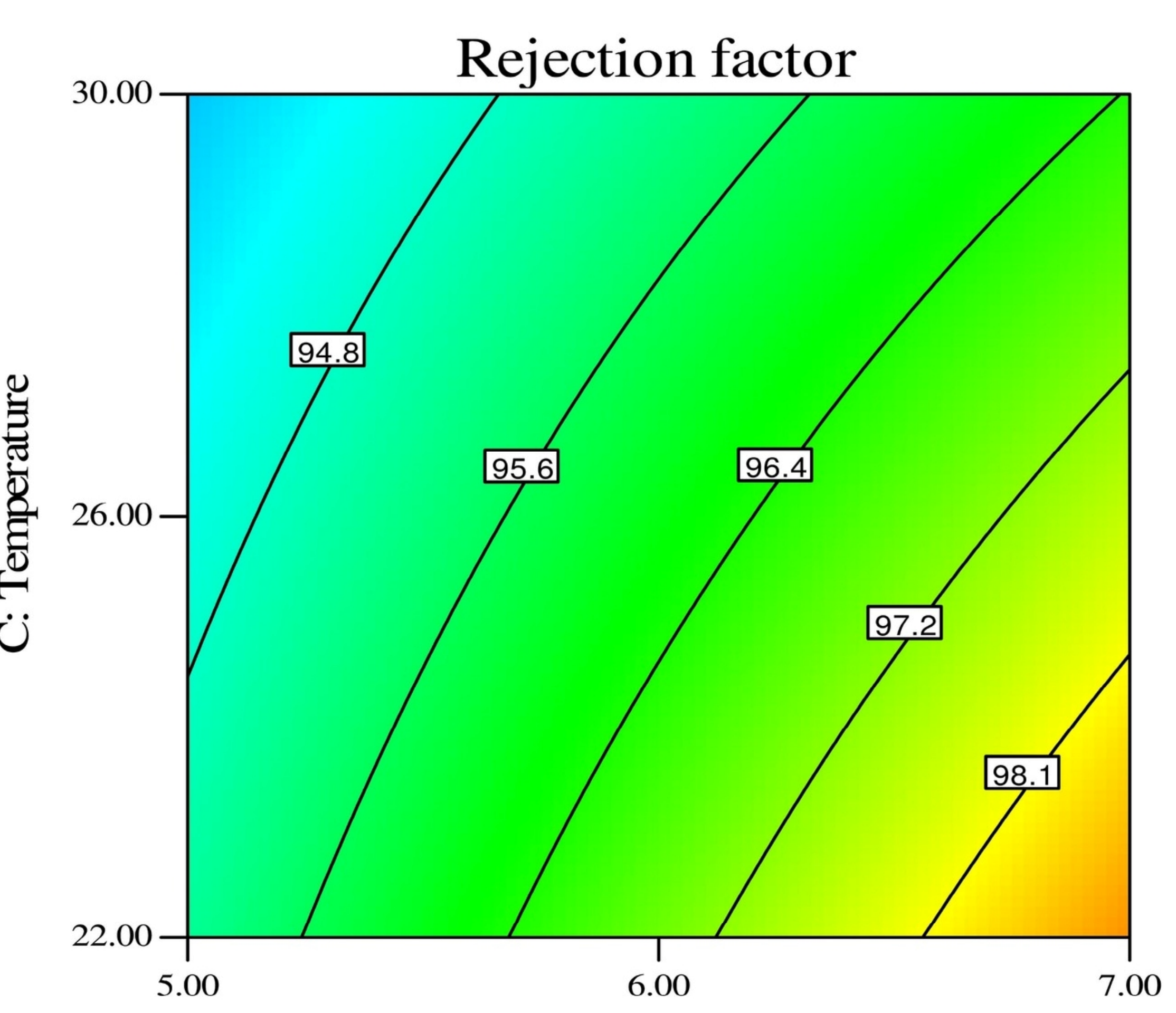

B: Pressure

Fig. 8. Correlation between experimental data and predicted values for SPF and SRE.

The antifouling properties of the membrane with and without $\mathrm{TiO}_{2}$ nanoparticles were investigated, while TMP and temperature were held constant at their center point ( 6 bar and $\left.26{ }^{\circ} \mathrm{C}\right)$. The flux decline analyses, SPF and stable PWF before and after filtration test are reported in Table 9. Obviously, the TFN membranes maintained higher fluxes, which indicates that the performance of 
the membrane was interestingly improved by the addition of $\mathrm{TiO}_{2}$ nanoparticles. The total fouling of the TFN0.02 and TFN0.04 membranes is lower than the TFC membrane, and the irreversible fouling has a little portion of the total fouling. The FRR of the TFN membranes is also higher than the TFC membrane, which means the addition of $\mathrm{TiO}_{2}$ nanoparticles into a PA layer not only increases its water permeability, but also enhances the fouling resistance of the membrane. The improved antifouling properties of the TFN membranes may be related to the improved hydrophilicity and less negative charged of the membrane surface. The less negative charge and hydrophilic surface of the TFN membrane could cause to reduce the interaction between sulfur compound and membrane surface and finally less fouling would be occurred [43].

Table 9. Antifouling properties and flux decline analyses for the TFC and TFN membranes.

\begin{tabular}{lcccccccc}
\hline \multirow{2}{*}{ Membrane } & \multicolumn{3}{c}{ Flux $(\mathrm{LMH})$} & & \multicolumn{4}{c}{ Flux decline (\%) } \\
\cline { 2 - 3 } \cline { 7 - 9 } & $\mathrm{J}_{\mathrm{w} 1}$ & $\mathrm{~J}_{\mathrm{w} 2}$ & $\mathrm{~J}_{\mathrm{p}}$ & & $\mathrm{R}_{\mathrm{r}}$ & $\mathrm{R}_{\mathrm{ir}}$ & $\mathrm{R}_{\mathrm{t}}$ & FRR \\
\hline TFC & $22.85 \pm 1.34$ & $18.95 \pm 0.49$ & 11.10 & & $34.35 \pm 0.15$ & $16.99 \pm 2.71$ & $51.34 \pm 1.86$ & $83 \pm 2.71$ \\
TFN0.02 & $25.20 \pm 1.56$ & $22.00 \pm 1.27$ & 13.00 & & $35.63 \pm 2.85$ & $12.69 \pm 0.34$ & $48.31 \pm 1.19$ & $87 \pm 0.33$ \\
TFN0.04 & $27.50 \pm 1.70$ & $25.00 \pm 0.57$ & 14.65 & & $37.64 \pm 0.27$ & $8.98 \pm 3.56$ & $46.63 \pm 1.29$ & $91 \pm 3.56$ \\
\hline
\end{tabular}

From the articles surveyed in this study, it is evident that NF membrane technology (TFN) provides the capability of selectivity in the rejection of divalent solutes and some monovalent ones at relatively low operating pressures. The permeate stream can thus directly be recycled and reused in the process. Moreover, the minimum and maximum SRE in this study at the worst and best conditions were $92.56 \%$ and $99.94 \%$, respectively. In such circumstance and with respect to the sulfate concentration in wastewater sample, TFN membrane could be effective separation process in desulfurization of SRU wastewater to meet stringent environmental regulations based on WHO and EPA. Thus, substantial progress has been achieved in desulfurization process. In addition, the findings of this investigation complement those of earlier studies. In this regard, Table 10 summarizes the characteristics of various treatment processes and their performance for desulfurization of similar wastewater published recently and compares those articles with the present study. It was observed that although other processes including biological treatment, microbial fuel cell (MFC), and oxidizing-roasting process have a similar removal efficiency, these type of processes have inherent 
problems including high cost and energy consumption. In our NF experiments, high removal efficiency and permeate flux can be simultaneously achieved using low-energy consumption (TMP is around 5-7 bar). Furthermore, the efficient removal of sulfur at low-to mid sulfur feed concentrations is a very important feature of NF membrane process. Usually, other hybrid separation processes are practical when initial sulfur feed concentrations are higher than normal level.

Table 10. Comparison of various treatment processes and their performance for desulfurization of similar wastewater.

\begin{tabular}{lccc}
\hline Type of process treatment & $\begin{array}{c}\text { Concentration of sulfur in feed } \\
(\mathrm{mg} / \mathrm{L})\end{array}$ & $\begin{array}{c}\text { SRE } \\
(\%)\end{array}$ & Ref. \\
\hline Biological treatment (1) & $400-2258(\mathrm{high} \mathrm{pH})$ & $>97 \%$ & {$[3]$} \\
Biological treatment (2) & 2600 & $75-95 \%$ & {$[7]$} \\
Microbial fuel cell & 1000 & $99 \%$ & {$[5]$} \\
Oxidizing-roasting process & 1700 & $>89 \%$ & {$[9]$} \\
1-butyl-3-methylimidazolium chloride & $50-1000$ & $49.31-77.21 \%$ & {$[11]$} \\
Present work & $1500-2000$ & $92.56-99.94 \%$ & \\
\hline
\end{tabular}

\section{Conclusions}

The main aim of the present research was to examine the performance of nanofiltration process in wastewater desulfurization of $\mathrm{SRU}$ using $\mathrm{TiO}_{2} / \mathrm{PA}$ TFN membrane. TFN membranes were successfully synthesized and characterized to tailor membrane structure and performance. According to the membrane characterization results, the surface properties including contact angle and morphology of ultra-thin upper layer were changed by increasing the content of $\mathrm{TiO}_{2}$ nanoparticles in the PA structure. The SEM/EDX, ATR-FTIR spectra and ICP-OES analysis of titanium confirmed the formation of PA and the presence of nanoparticles on the surface of the prepared membranes. The separation experiments revealed that the incorporation of nanoparticles in PA top layer can effectively increase SPF due to the enhanced hydrophilicity and fouling resistant of membrane surface. Also, the increase of operating temperature decreased the SRE, while the increase of $\mathrm{TiO}_{2}$ concentration and TMP enhanced it. The statistical and mathematical model which is developed using CCF is found to be reliable and reasonably precise, and can be used for prediction within the limits of the factors studied. Furthermore, the ANOVA analysis revealed that the empirical models based on the main 
effects and their interactions were satisfied to interpret the results. Consequently, there is no significant curvature in the design space. Moreover, the predicted values in comparison with experimental data illustrated that there was a satisfactory agreement between them. The best sulfate retention was obtained with membranes having maximum amount of $\mathrm{TiO}_{2}$ and when the highest pressure was used. The permeate flux of $16.3 \mathrm{LMH}$ and sulfate retention of $99.9 \%$ was achieved at a pressure of 7 bar. Although the current study is based on a small sample of sour wastewater, the findings suggest the method used for this wastewater may be applied to other SRU wastewater elsewhere in the world. Also, notwithstanding all limitations, the study suggests that NF process with TFN membranes can be considered in various wastewater treatment application as an economical technique (especially for sulfur treatment) which is applied in low- to mid-operating pressure. All in all, the findings of this study have a number of important implications for future practice and can be useful in achieving the practical application in desulfurization process of aforementioned wastewater for large scale production.

\section{Acknowledgements}

Mr. Toni Väkiparta (laboratory technician, LUT School of Engineering Science) is appreciatively acknowledged for his assistant in SEM analysis.

\section{Supplementary material}

Supplementary data to this article can be found online at https://doi.org/10.1016/j.seppur.2019.03.096.

\section{References}

[1] K. Kuklinska, M.C.L. Wolska, J. Namiesnik, Analytical and bioanalytical problems associated with the toxicity of elemental sulfur in the environment, Trends. Anal. Chem. 48 (2013) 14-21.

[2] F.T. Last, Effects of atmospheric sulphur compounds on natural and man-made terrestrial and aquatic ecosystems, Agr. Environ. 7 (1982) 299-387. 
[3] H. Kamori, M. Fujii, K. Fukunaga, M. Sakata, K. Aritome, O. Miki, N. Kanemori, Y. Matsubara, Biological treatment of high-pH and sulfur compound-contaminated wastewater, Nippon Steel Technical Report 70 (1996) 7-14.

[4] K.L. Ho, Y.C. Chung, Y.H. Lin, C.P. Tseng, Microbial populations analysis and field application of biofilter for the removal of volatile-sulfur compounds from swine wastewater treatment system, J. Hazard. Mater. 152 (2008) 580-588.

[5] F.Y. Liang, H. Deng, F. Zhao, Sulfur pollutants treatment using microbial fuel cells from perspectives of electrochemistry and microbiology, Chinese J. Anal. Chem. 41 (2013) 1133-1139.

[6] M. Winter, R. Kickuth, Elimination of sulphur compounds from wastewater by the root zone process-II. Mode of formation of sulphur deposits, Water Res. 23 (1989) 547-560.

[7] G. Chen, H.K. Chui, H. Lu, D. Wu, T. Hao, F. Jiang, M.C.M. Van loosdrecht, Biological wastewater treatment and reuse utilizing sulfur compounds as electron carrier to minimize sludge production, US Patent 0256223 A1, 2013.

[8] E. Vega, M.J. Martin, R. Gonzalez-Olmos, Integration of advanced oxidation processes at mild conditions in wet scrubbers for odourous sulphur compounds treatment, Chemosphere 109 (2014) $113-119$.

[9] X.L. Hu, W.M. Chen, Q.L. Xie, Sulfur phase and sulfur removal in high sulfur-containing bauxite, Trans. Nonferrous Met. Soc, China 21 (2011) 1641-1647.

[10] F.A. Duarte, P.A. Mello, C.A. Bizzi, M.A.G. Nunes, E.M. Moreira, M.S. Alencar, H.N. Motta, V.L. Dressler, E.M.M. Flores, Sulfur removal from hydrotreated petroleum fractions using ultrasound-assisted oxidative desulfurization process, Fuel 90 (2011) 2158-2164.

[11] S.A. Dharaskar, K.L. Wasewar, M.N. Varma, D.Z. Shende, C.K. Yoo, Deep removal of sulfur from model liquid fuels using 1-Butyl-3-Methylimidazolium Chloride, Procedia Eng. 51 (2013) 416422.

[12] M. Ahmed, A. Rahim, Chemical desulphurization methods of organic sulphur of Eocene coal, Jaintia Hills, Meghalaya, Coal Sci. Technol. 24 (1995) 1721-1724. 
[13] X.L. Wang, H.L. Fan, Z. Tian, E.Y. He, Y. Li, J. Shangguan, Adsorptive removal of sulfur compounds using IRMOF-3 at ambient temperature, Appl. Surf. Sci. 289 (2014) 107-113.

[14] R. Markuszewski, B.D. Blaustein, Fossil fuels utilization: environmental concerns. Washington DC, ACS publishing, 1986.

[15] Y. Mochizuki, K. Sugawara, Selective adsorption of organic sulfur in coal extract by using metalloaded carbon, Fuel 90 (2011) 2974-2980.

[16] L. Jin, Q. Cao, J. Li, J. Dong, Sulfur removal in coal tar pitch by oxidation with hydrogen peroxide catalyzed by trichloroacetic acid and ultrasonic waves, Fuel 90 (2011) 3456-3460.

[17] D. Uzun, S. Ozdogan, Sulfur removal from original and acid treated lignites by pyrolysis, Fuel 85 (2006) 315-322.

[18] N. Yin, F. Liu, Z. Zhong, W. Xing, Integrated membrane process for the treatment of desulfurization wastewater, Ind. Eng. Chem. Res. 49 (2010) 3337-3341.

[19] X. He, M.B. Hagg, Membranes for environmentally friendly energy processes, Membranes 2 (2012) 706-726.

[20] S. Shirazi, C.J. Lin, D. Chen, Inorganic fouling of pressure-driven membrane processes - A critical review, Desalination 250 (2010) 236-248.

[21] T. Humplik, J. Lee, S.C. O’Hern, B.A. Fellman, M.A. Baig, S.F. Hassan, M.A. Atieh, F. Rahman, T. Laoui, R. Karnik, E.N. Wang, Nanostructured materials for water desalination, Nanotechnology $22(2011) 1-19$.

[22] M. Namvar-Mahboub, M. Pakizeh, S. Davari, Preparation and characterization of UZM 5/polyamide thin film nanocomposite membrane for dewaxing solvent recovery, J. Membr. Sci. 459 (2014) 22-32.

[23] N. Niksefat, M. Jahanshahi, A. Rahimpour, The effect of $\mathrm{SiO}_{2}$ nanoparticles on morphology and performance of thin film composite membranes for forward osmosis application, Desalination 343 (2014) 140-146. 
[24] N. Rakhshan, M. Pakizeh, Removal of triazines from water using a novel OA modified $\mathrm{SiO}_{2} / \mathrm{PA} / \mathrm{PSf}$ nanocomposite membrane, Sep. Purif. Technol. 147 (2015) 245-256.

[25] B. Rajaeian, A. Rahimpour, M.O. Tade, S. Liu, Fabrication and characterization of polyamide thin film nanocomposite (TFN) nanofiltration membrane impregnated with $\mathrm{TiO}_{2}$ nanoparticles, Desalination 313 (2013) 176-188.

[26] A. Mayyahi, $\mathrm{TiO}_{2}$ polyamide thin film nanocomposite reverses osmosis membrane for water desalination, Membranes 8(3) (2018) 66.

[27] N. Cheshomi, M. Pakizeh, M. Namvar-Mahboub, Preparation and characterization of $\mathrm{TiO}_{2} /$ Pebax/(PSf-PES) thin film nanocomposite membrane for humic acid removal from water, Polym. Adv. Technol. 29 (4) (2018) 1303-1312.

[28] G. Lai, W. Lau, S. Gray, T. Matsuura, R. Jamshidi Gohari, M.N. Subramanian, S.O. Lai, C.S. Ong, A.F. Ismail, D. Emazadeh, M. Ghanbari, A practical approach to synthesize polyamide thin film nanocomposite (TFN) membranes with improved separation properties for water/wastewater treatment, J. Mat. Chem. A. 4 (11) (2016) 4134-4144.

[29] S. Kim, P. Lee, S. Bano, Y. Park, S. Nam, K. Lee, Effective incorporation of $\mathrm{TiO}_{2}$ nanoparticles into polyamide thin-film composite membranes, J. Appl. Polym. Sci. 133 (18) (2016) 43383-43395. [30] D. Emadzadeh, W. Lau, T. Matsuura, A.F. Ismail, M. Rahbari-Sisakht, Synthesis and characterization of thin film nanocomposite forward osmosis membrane with hydrophilic nanocomposite support to reduce internal concentration polarization, J. Membr. Sci. 449 (2014) 7485.

[31] A. Rodriguez-Calvo, G.A. Silva-Castro, F. Osorio, J. Gonzalez-Lopez, C. Calvo, Novel membrane materials for reverse osmosis desalination, Hydrol. Current Res. 5 (2014) 1-7.

[32] S. Daer, J. Kharraz, A. Giwa, S.W. Hasan, Recent applications of nanomaterials in water desalination: A critical review and future opportunities, Desalination 367 (2015) 37-48.

[33] G.L. Jadav, P.S. Singh, Synthesis of novel silica-polyamide nanocomposite membrane with enhanced properties, J. Membr. Sci. 328 (2009) 257-267. 
[34] H. Azizi Namaghi, A. Haghighi Asl, M. Pourafshari Chenar, Identification and optimization of key parameters in preparation of thin film composite membrane for water desalination using multistep statistical method, J. Ind. Eng. Chem. 31 (2015) 61-73.

[35] V. Vatanpour, M. Sheydaei, M. Esmaeili, Box-Behnken design as a systematic approach to inspect correlation between synthesis conditions and desalination performance of TFC RO membranes, Desalination 420 (2017) 1-11.

[36] M. Zargar, B. Jin, S. Dai, An integrated statistic and systematic approach to study correlation of synthesis condition and desalination performance of thin film composite membranes, Desalination 394 (2016) 138-147.

[37] A. Idris, F. Kormin, M. Noordin, Application of response surface methodology in describing the performance of thin film composite membrane, Sep. Purif. Technol. 49 (3) (2006) 271-280.

[38] B. Khorshidi, T. Thundat, B. Fleck, M. Sadrzadeh, Thin film composite polyamide membranes: parametric study on the influence of synthesis conditions, RSC Adv. 5(68) (2015) 54985-54997.

[39] H.P. Ngang, A.L. Ahmad, S.C. Low, B.S. Ooi, Preparation of mixed-matrix membranes for micellar enhanced ultrafiltration based on response surface methodology, Desalination 293 (2012) 7-20.

[40] W.J. Lau, S. Gray, T. Matsuura, D. Emadzadeh, J. Paul Chen, A.F. Ismail, A review on polyamide thin film nanocomposite (TFN) membranes: history, applications, challenges and approaches, Water Res. 80 (2015) 306-324.

[41] J. Yin, E.S. Kim, J. Yang, B. Deng, Fabrication of a novel thin-film nanocomposite (TFN) membrane containing MCM-41 silica nanoparticles (NPs) for water purification, J. Membr. Sci. 423424 (2012) 238-246.

[42] V. Vatanpour, S.S. Madaeni, A.R. Khataee, E. salehi, S. Zinadini, H. Ahmadi Monfared, $\mathrm{TiO}_{2}$ embedded mixed matrix PES nanocomposite membranes: Influence of different sizes and types of nanoparticles on antifouling and performance, Desalination 292 (2012) 19-29.

[43] M. Golpour, M. Pakizeh, Preparation and characterization of new PA-MOF/PPSU-GO membrane for the separation of KHI from water, Chem. Eng. J. 345 (2018) 221-232. 
[44] K. Mammar, A. Chaker, A central composite face-centered design for parameters estimation of PEM fuel cell electrochemical model, Leonardo J. Sci. 23 (2013) 84-96.

[45] J. Meijer, G. Van Rosmalen, Solubilities and supersaturations of calcium sulfate and its hydrates in seawater, Desalination 51 (3) (1984) 255-305.

[46] M. Goosen, S. Sablani, S. Al-Maskari, R. Al-Belushi, M. Wilf, Effect of feed temperature on permeate flux and mass transfer coefficient in spiral-wound reverse osmosis systems, Desalination $144(1-3)(2002) 367-372$.

[47] S. Agashichev, Reverse osmosis at elevated temperatures: influence of temperature on degree of concentration polarization and transmembrane flux, Desalination 179 (1-3) (2005) 61-72.

[48] X. Jin, A. Jawor, S. Kim, Eric M. V. Hoek, Effects of feed water temperature on separation performance and organic fouling of brackish water RO membranes, Desalination 239 (1-3) (2009) 346-359.

[49] A. Jawor, Eric M. V. Hoek, Effects of feed water temperature on inorganic fouling of brackish water RO membranes, Desalination 235 (1-3) (2009) 44-57.

[50] A. Kazemi Beydokhty, H. Azizi Namaghi, S. Zeinali Heris, Identification of the key variables on thermal conductivity of $\mathrm{CuO}$ nanofluid by a fractional factorial design approach, Numer. Heat Transfer Part B 64 (2013) 480-495.

[51] B. Rahmanian, M. Pakizeh, S.A.A. Mansoori, R. Abedini, Application of experimental design approach and artificial neural network (ANN) for the determination of potential micellar-enhanced ultrafiltration process, J. Hazard. Mater. 187 (2011) 67-74.

[52] C.Y. Tang, Y.N. Kwon, J.O. Leckie, Effect of membrane chemistry and coating layer on physiochemical properties of thin film composite polyamide RO and NF membranes I. FTIR and XPS characterization of polyamide and coating layer chemistry, Desalination 242 (2009) 149-167.

[53] M. Fathizadeh, A. Aroujalian, A. Raisi, Effect of added NaX nano-zeolite into polyamide as a top thin layer of membrane on water flux and salt rejection in a reverse osmosis process, J. Membr. Sci. 375 (2011) 88-95. 
[54] Z. Yang, J. Yin, B. Deng, Enhancing water flux of thin-film nanocomposite (TFN) membrane by incorporation of bimodal silica nanoparticles, AIMS Environ. Sci. 3 (2) (2016) 185-198.

[55] G.N.B. Barona, J. Lim, M. Choi, B. Jung, Interfacial polymerization of polyamide-aluminosilicate SWNT nanocomposite membranes for reverse osmosis, Desalination 325 (2013) 138-147.

[56] L. Ni, J. Meng, X. Li, Y. Zhang, Surface coating on the polyamide TFC RO membrane for chlorine resistance and antifouling performance improvement, J. Membr. Sci. 451 (2014) 205-215. [57] S. Belfer, R. Fainchtain, Y. Purinson, O. Kedem, Surface characterization by FTIR-ATR spectroscopy of polyethersulfone membranes-unmodified, modified and protein fouled, J. Membr. Sci. 172 (2000) 113-124.

[58] D. Emadzadeh, W.J. Lau, M. Rahbari-Sisakht, H. Ilbeygi, D. Rana, T. Matsuura, A.F. Ismail, Synthesis, modification and optimization of titanate nanotubes-polyamide thin film nanocomposite (TFN) membrane for forward osmosis (FO) application, Chem. Eng. J. 281 (2015) 243-251.

[59] W. Xie, G.M. Geise, B.D. Freeman, H.S. Lee, G. Byun, J.E. McGrath, Polyamide interfacial composite membranes prepared from m-phenylene diamine, trimesoyl chloride and a new disulfonated diamine, J. Membr. Sci. 403-404 (2012) 152-161.

[60] B.M. Ganesh, Arun M. Isloor, A.F. Ismail, Enhanced hydrophilicity and salt rejection study of graphene oxide-polysulfone mixed matrix membrane, Desalination 313 (2013) 199-207.

[61] A. Rahimpour, M. Jahanshahi, B. Rajaeian, M. Rahimnejad, $\mathrm{TiO}_{2}$ entrapped nanocomposite PVDF/SPES membranes: Preparation, characterization, antifouling and antibacterial properties, Desalination 278 (2011) 343-353.

[62] P.S. Singh, S.V. Joshi, J.J. Trivedi, C.V. Devmurari, A.P. Rao, P.K. Ghosh, Probing the structural variations of thin film composite RO membranes obtained by coating polyamide over polysulfone membranes of different pore dimensions, J. Membr. Sci. 278 (2006) 19-25.

[63] N. Misdan, W.J. Lau, A.F. Ismail, T. Matsuura, Formation of thin film composite nanofiltration membrane: Effect of polysulfone substarte characteristics, Desalination 329 (2013) 9-18. 
[64] V. Freger, Kinetics of film formation by interfacial polycondensation, Langmuir 21 (5) (2005) 1884-1894.

[65] T. Ostomel, P. Stoimenov, P. Holden, H. Alam, G. Stucky, Host-guest composites for induced hemostasis and therapeutic healing in traumatic injuries, J Thromb Thrombolysis. 22 (1) (2006) 5567.

[66] S. Kim, S. Kwak, T. Suzuki, Positron annihilation spectroscopic evidence to demonstrate the flux-enhancement mechanism in morphology-controlled thin-film-composite (TFC) membrane, Environ. Sci. Technol. 39 (6) (2005) 1764-1770.

[67] S. Kwak, S. Jung, S. Kim, Structure-motion-performance relationship of flux-enhanced reverse osmosis (RO) membranes composed of aromatic polyamide thin films, Environ. Sci. Technol. 35 (21) (2001) 4334-4340.

[68] A.K. Ghosh, B.H. Jeong, X. Huang, E.M.V. Hoek, Impacts of reaction and curing conditions on polyamide composite reverse osmosis membrane properties, J. Membr. Sci. 311 (2008) 34-45.

[69] B. Khorshidi, T. Thundat, B.A. Fleck, M. Sadrzadeh, A novel approach toward fabrication of high performance thin film composite polyamide membranes, Sci. Rep. 6:22069 (2016) 1-10.

[70] L. Wang, M. Fang, J. Liu, J. He, L. Deng, J. Li, J. Lei, The influence of dispersed phases on polyamide/ZIF-8 nanofiltration membranes for dye removal from water, RSC Advances, 5(63) (2015) 50942-50954.

[71] H. Huang, X. Qu, H. Dong, L. Zhang, H. Chen, Role of NaA zeolites in the interfacial polymerization process towards a polyamide nanocomposite reverse osmosis membrane, RSC Adv. 3 (22) (2013) 8203-8207.

[72] M. Lind, A. Ghosh, A. Jawor, X. Huang, W. Hou, Y. Yang, E.M.V. Hoek, Influence of zeolite crystal size on zeolite-polyamide thin film nanocomposite membranes, Langmuir 25 (17) (2009) 10139-10145.

[73] J. Cañas-Carrell, S. Li, A. Parra, B. Shrestha, Health and Environmental Safety of Nanomaterials. Polymer Nancomposites and Other Materials Containing Nanoparticles, Woodhead, 1st Ed., 2014. 
[74] V. Sharma, Aggregation and toxicity of titanium dioxide nanoparticles in aquatic environmentA Review, J. Environ. Sci. Health A. 44 (14) (2009) 1485-1495.

[75] Y. Ju-Nam, J. Lead, Manufactured nanoparticles: An overview of their chemistry, interactions and potential environmental implications, Sci. Total Environ. 400 (1-3) (2008) 396-414.

[76] J. Zhu, L. Qin, A. Andrew Uliana, J. Hou, J. Wang, Y. Zhang, X. Li, S. Yuan, J. Li, M. Tian, J. Lin, B. Van der Bruggen, Elevated performance of thin film nanocomposite membranes enabled by modified hydrophilic MOFs for nanofiltration, Appl. Mater. Interfaces 9 (2) (2017) 1975-1986.

[77] Amy E. Childress, M. Elimelech, Effect of solution chemistry on the surface charge of polymeric reverse osmosis and nanofiltration membranes, J. Membr. Sci. 119 (1996) 253-268.

[78] S. Wang, Z. Yi, X. Zhao, Y. Zhou, C. Gao, Aggregation suppressed thin film nanocomposite (TFN) membranes prepared with an in situ generation of $\mathrm{TiO}_{2}$ nanoadditives, RSC. Adv. 7 (2017) $26136-26144$.

[79] H. Azizi Namaghi, S.M. Mousavi, Factorial experimental design for treatment of an industrial wastewater using micellar-enhanced ultrafiltration, Desalin. Water Treat. 57 (2016) 5416-5424.

[80] S. Madani, R. Gheshlaghi, M. Akhavan Mahdavi, M. Sobhani, A. Elkamel, Optimization of the performance of a double-chamber microbial fuel cell through factorial design of experiments and response surface methodology, Fuel 150 (2015) 434-440.

[81] M. Yuan, V.R. Joseph, Y. Lin, An efficient variable selection approach for analyzing designed experiments, Technometrics 49 (2007) 430-439.

[82] A. Hafizi, A. Ahmadpour, M. Koolivand-Salooki, M.M. Heravi, F.F. Bamoharram, Comparison of RSM and ANN for the investigation of linear alkylbenzene synthesis over $\mathrm{H}_{14}\left[\mathrm{NaP}_{5} \mathrm{~W}_{30} \mathrm{O}_{110}\right] / \mathrm{SiO}_{2}$ catalyst, J. Ind. Eng. Chem. 19 (2013) 1981-1989.

[83] P. Onsekizoglu, K.S. Bahceci, J. Acar, The use of factorial design for modeling membrane distillation, J. Membr. Sci. 349 (2010) 225-230. 
[84] N. Alghezawi, O. Sanl, L. Aras, G. Asman, Separation of acetic acid-water mixtures through acrylonitrile grafted poly(vinyl alcohol) membranes by pervaporation, Chem. Eng. Process. 44 (2005) $51-58$.

[85] Y. Jafarzadeh, R. Yegani, Analysis of fouling mechanisms in $\mathrm{TiO}_{2}$ embedded high density polyethylene membranes for collagen separation, Chem. Eng. Res. Des. 93 (2015) 684-695.

[86] Y. Fang, Study of the effect of surface morphology on mass transfer and fouling behavior of reverse osmosis and nanofiltration membrane processes, Ph.D. Thesis University of Central Florida Orlando, Florida, USA, 2013.

[87] B.H. Jeong, E.M.V. Hoek, Y. Yan, A. Subramani, X. Huang, G. Hurwitz, A.K. Ghosh, A. Jawor, Interfacial polymerization of thin film nanocomposites: A new concept for reverse osmosis membranes. J. Membr. Sci. 294 (2007) 1-7.

[88] R.R. Sharma, R. Agrawal, S. Chellam, Temperature effects on sieving characteristics of thinfilm composite nanofiltration membranes: pore size distributions and transport parameters, J. Membr. Sci. 223 (2003) 69-87.

[89] S. Zhao, L. Zou, Effects of working temperature on separation performance, membrane scaling and cleaning in forward osmosis desalination, Desalination 278 (2011) 157-164.

[90] F.A. Pacheco Oreamuno, Microscopic Characterization of the Nanostructure of Polyamide Thin Films in Reverse Osmosis and Nanofiltration Membranes, Ph.D. Thesis University of Stanford, California, USA, 2011.

[91] A. Peyki, A. Rahimpour, M. Jahanshahi, Preparation and characterization of thin film composite reverse osmosis membranes incorporated with hydrophilic SiO2 nanoparticles, Desalination 368 (2015) 152-158.

[92] R. Ruby-Figueroa, A. Cassano, E. Drioli, Ultrafiltration of orange press liquor: Optimization of operating conditions for the recovery of antioxidant compounds by response surface methodology, Sep. Purif. Technol. 98 (2012) 255-261. 
[93] T. Yaseen Khalaf, Effect of feed temperature on concentration polarization and efficiency of reverse osmosis systems, The $1^{\text {st }}$ Regional Conference of Eng. Sci. NUCEJ Spatial 11 (2008) 145-152. 


\section{Caption of Figures}

Fig. 1. Schematic of CCF design for the three factors.

Fig. 2. ATR-FTIR spectra of PSf and PA-TFN membranes.

Fig. 3. Schematic of interaction and self-assembly between $\mathrm{TiO}_{2}$ nanoparticles and $\mathrm{TMC}$ during PA synthesis.

Fig. 4. SEM surface morphology of PA membranes (A) TFN0.00, (B) TFN0.02 and (C) TFN0.04.

Fig. 5. AFM images of TFC and TFN membranes.

Fig. 6. SEM images of TFN0.04 membranes before (A) and after (B) chlorine exposure.

Fig. 7. The variation of zeta potential versus $\mathrm{pH}$ for TFN membranes.

Fig. 8. Correlation between experimental data and predicted values for SPF and SRE. 


\section{Table legends}

Table 1. Actual design variables with real and coded values for the CCF.

Table 2. Design layout and experimental points of the CCF.

Table 3. EDX Results for TFC and modified TFC Membranes with 0.02 and $0.04 \mathrm{wt} \% \mathrm{TiO}_{2} \mathrm{NPs}_{\text {. }}$

Table 4. Surface roughness parameters of TFC and TFN membranes.

Table 5. Real content of $\mathrm{TiO}_{2}$ nanoparticle in TMC solution and PA layer.

Table 6. Ti element detected (released) in feed and permeate samples of TFN0.04 during $2 \mathrm{~h}$ filtration test.

Table 7. ANOVA for selected SPF model.

Table 8. ANOVA for selected SRE model.

Table 9. Antifouling properties and flux decline analyses for the TFC and TFN membranes.

Table 10. Comparison of various treatment processes and their performance for desulfurization of similar industrial wastewater. 